\title{
Surface energy balance sensitivity to meteorological variability on Haig Glacier, Canadian Rocky Mountains
}

\author{
Samaneh Ebrahimi and Shawn J. Marshall \\ Department of Geography, University of Calgary, 2500 University Drive Northwest, Calgary, \\ Alberta, T2N 1N4, Canada \\ Correspondence to: Samaneh Ebrahimi (samaneh.ebrahimi@ucalgary.ca)
}

Received: 12 January 2016 - Published in The Cryosphere Discuss.: 29 January 2016

Revised: 15 October 2016 - Accepted: 18 October 2016 - Published: 18 November 2016

\begin{abstract}
Energy exchanges between the atmosphere and the glacier surface control the net energy available for snow and ice melt. This paper explores the response of a midlatitude glacier in the Canadian Rocky Mountains to daily and interannual variations in the meteorological parameters that govern the surface energy balance. We use an energy balance model to run sensitivity tests to perturbations in temperature, specific humidity, wind speed, incoming shortwave radiation, glacier surface albedo, and winter snowpack depth. Variables are perturbed (i) in isolation, (ii) including internal feedbacks, and (iii) with co-evolution of meteorological perturbations, derived from the North American regional climate reanalysis (NARR) over the period 1979-2014. Summer melt at this site has the strongest sensitivity to interannual variations in temperature, albedo, and specific humidity, while fluctuations in cloud cover, wind speed, and winter snowpack depth have less influence. Feedbacks to temperature forcing, in particular summer albedo evolution, double the melt sensitivity to a temperature change. When meteorological perturbations covary through the NARR forcing, summer temperature anomalies remain important in driving interannual summer energy balance and melt variability, but they are reduced in importance relative to an isolated temperature forcing. Covariation of other variables (e.g., clear skies, giving reduced incoming longwave radiation) may be partially compensating for the increase in temperature. The methods introduced in this paper provide a framework that can be extended to compare the sensitivity of glaciers in different climate regimes, e.g., polar, maritime, or tropical environments, and to assess the importance of different meteorological parameters in different regions.
\end{abstract}

\section{Introduction}

Glaciers and ice fields are thinning and retreating in all of the world's mountain regions in response to global climate change (e.g., Marzeion et al., 2014). This is reshaping alpine environments, affecting regional water resources, and contributing to global sea-level rise (e.g., Radić and Hock, 2011). A glacier's climate sensitivity can be expressed in terms of the energy or mass balance response to a change in meteorological conditions (Oerlemans and Fortuin, 1992; Oerlemans et al., 1998). For instance, Oerlemans et al. (1998) defined the static glacier sensitivity to temperature, $S_{T}, i$ as

$S_{T}=\frac{\partial B_{\mathrm{m}}}{\partial T} \approx \frac{B_{\mathrm{m}}(+1 K)-B_{\mathrm{m}}(-1 K)}{2}$,

where $\delta B_{\mathrm{m}}(T)$ denotes the mean specific mass balance corresponding to the temperature perturbation $\delta T$. Mass balance sensitivity to precipitation perturbations, $S_{\mathrm{P}}=\partial B_{\mathrm{m}} / \partial P$, can be calculated in the same way.

Braithwaite and Raper (2002) extended the static sensitivity approach to regional scales, with the idea that glaciers within a given climate regime should have similar mass balance sensitivities to variations in temperature and precipitation. This framework has been used in numerous studies to describe glacier sensitivity to climate change (e.g., Dyurgerov, 2001; Klok and Oerlemans, 2004; Arendt et al., 2009; Anderson et al., 2010; Engelhardt et al., 2015).

Most studies to date have concentrated on glacier mass balance response to changes in temperature and precipitation. This is sensible, as these are generally the most important meteorological variables affecting glacier mass balance. These two fields are also commonly measured, with long-term records available in many regions. Temperature 
and precipitation have also received the most attention because regional- to global-scale models of glacier mass balance commonly employ temperature-index methods to parameterize glacier melt (e.g., Marzeion et al., 2014; Clarke et al., 2015), with only these variables as inputs.

While temperature-index models have demonstrated reasonable skill in estimating seasonal melt (Ohmura, 2001; Hock, 2005), they are nonetheless missing much of the physics that govern melt. Also, they may be overly sensitive to changes in temperature, without effectively capturing the impact of shifts in other variables such as wind, humidity, or cloud cover. Internal processes and feedbacks, such as surface albedo evolution, may also be absent, since degree-day melt factors are usually taken to be static. Such feedbacks are critical to glacier melt (e.g., Brock et al., 2000; Klok and Oerlemans, 2004; Cuffey and Paterson, 2010).

It is uncertain whether variability in glaciometeorological variables other than temperature and precipitation is important to glacier energy and mass balance. While most largescale glacier change projections are rooted in temperature sensitivity (as built into temperature-index models), it is generally recognized that the complete surface energy balance is important to glacier melt. For instance, net radiation has been identified as the main source of melt energy for continental glaciers, accounting for $\sim 70-80 \%$ of the total melt energy (e.g., Greuell and Smeets, 2001; Oerlemans and Klok, 2002; Klok et al., 2005; Giesen et al., 2008), with shortwave radiation providing the principal energy source. Incoming shortwave radiation is not directly dependent on temperature. As another example, latent heat fluxes are a significant source of energy in maritime and tropical environments (Wagnon et al., 1999, 2003; Favier et al., 2004; Anderson et al., 2010), and their strength is a function of humidity and wind conditions, which are not strongly correlated with temperature fluctuations. This calls for a broader exploration of glacier sensitivity to climate variability and change, beyond just the influence of temperature.

Several studies that estimate glacier sensitivity to temperature change use complete models of energy balance (e.g., Klok and Oerlemans, 2004; Klok et al., 2005; Anslow et al., 2008; Anderson et al., 2010). The influence of other meteorological variables has been explored in a few studies. Gerbaux et al. (2005) examine the role of different variables (e.g., temperature, moisture, wind) in energy balance processes and climate sensitivity in the French Alps. Giesen et al. (2008) note the importance of cloud cover in modulating interannual variability in summer melt on Midtdalsbreen, Norway. Sicart et al. (2008) examine three glaciers in different latitudes/climate regimes. Variations in net shortwave radiation, sensible heat flux, and temperature each contribute to differences in glacier sensitivity to climate variability between these locations.

We build on these studies through a systematic examination of glacier energy balance and melt sensitivity. We report the mean melt season conditions on Haig Glacier in the Cana- dian Rocky Mountains for the period 2002-2012. These reference data are used as a baseline for theoretical and numerically modelled sensitivity. The same perturbation approach is then used to reconstruct variations in surface energy balance and melt for the period 1979-2014, based on North American regional climate reanalyses (NARR) (Mesinger et al., 2006). Our main question is whether variables other than temperature and precipitation need to be considered to provide a realistic estimate of glacier sensitivity to climate change for midlatitude mountain glaciers. Our analysis in this study is limited to just one site, with a focus on the summer melt season (vs. annual mass balance). We examine the summer energy balance and evaluate the impact of different variables in isolation and with more realistic covariance of meteorological conditions.

\section{Surface energy balance and melt model}

The energy budget at the glacier surface is defined by the fluxes of energy between the atmosphere, the snow/ice surface, and the underlying snow or ice. The surface energy balance can be written

$Q_{\mathrm{N}}=Q_{\mathrm{S}}^{\downarrow}(1-\alpha)+Q_{\mathrm{L}}^{\downarrow}-Q_{\mathrm{L}}^{\uparrow}+Q_{\mathrm{H}}+Q_{\mathrm{E}}+Q_{\mathrm{C}}$,

where $Q_{\mathrm{N}}$ is the net energy flux at the surface and $Q_{\mathrm{S}}^{\downarrow}, Q_{\mathrm{L}}^{\downarrow}$, $Q_{\mathrm{L}}^{\uparrow}, Q_{\mathrm{H}}, Q_{\mathrm{E}}$, and $Q_{\mathrm{C}}$ represent incoming shortwave radiation, incoming and outgoing longwave radiation, sensible and latent heat flux, and subsurface conductive energy flux, respectively. The energy fluxes have the units $\mathrm{W} \mathrm{m}^{-2}$. The surface albedo is denoted $\alpha$ and fluxes are defined to be positive when they are sources of energy to the glacier surface. We neglect the penetration of shortwave radiation and advection of energy by precipitation and meltwater fluxes.

The net energy $Q_{\mathrm{N}}$ can be positive or negative. When it is negative, as it is for much of the winter and during the night, the snow or ice will cool or liquid water will refreeze. Positive net energy will drive surface warming or, on a melting glacier surface with $Q_{\mathrm{N}}>0$, the net energy flux is dedicated to generating surface melt. For melt rate $\dot{m}$, this follows

$\dot{m}=\frac{Q_{\mathrm{N}}}{\rho_{\mathrm{w}} L_{\mathrm{f}}}$,

where $\rho_{\mathrm{W}}$ is the density of water and $L_{\mathrm{f}}$ is the latent heat of fusion. Melt rates in Eq. (3) have units of metres water equivalent per second ( $\mathrm{m}$ w.e. $\left.\mathrm{s}^{-1}\right)$.

Numerous studies have shown that incoming shortwave radiation is the dominant term in the energy balance during the melt season in most glacial environments. Incoming shortwave radiation (insolation) at the surface has three components: direct and diffuse solar radiation as well as direct solar radiation that is reflected from the surrounding terrain. Direct solar radiation is the radiative flux from the direct solar beam, which comes in at a zenith angle $Z$. It is a function 
of latitude, time of year, and time of day (e.g., Oke, 1987). Potential direct (clear-sky) incoming solar radiation on a horizontal surface can be estimated from

$$
Q_{\varphi}^{\downarrow}=Q_{0} \cos (Z) \varphi_{0}^{P / P_{0} \cos (Z)}
$$

for top-of-atmosphere insolation $Q_{0}$, clear-sky atmospheric transmissivity $\varphi_{0}$, air pressure $P$, and sea-level air pressure $P_{0}$ (Oke, 1987). Equation (4) allows potential direct shortwave radiation to be calculated as a function of the day, year, latitude, and elevation.

Longwave radiation can be estimated from the StefanBoltzmann equation

$Q_{\mathrm{L}}=\varepsilon \sigma T^{4}$,

where $\varepsilon$ is the thermal emissivity, $\sigma$ is the Stefan-Boltzmann constant, and $T$ is the absolute temperature of the emitting surface. Snow and ice emit as near-perfect blackbodies at infrared wavelengths, with surface emissivity $\varepsilon_{\mathrm{s}}=0.98-1.0$. The longwave fluxes are then

$Q_{\mathrm{L}}^{\uparrow}=\varepsilon_{\mathrm{S}} \sigma T_{\mathrm{S}}^{4}$

and

$Q_{\mathrm{L}}^{\downarrow}=\varepsilon_{\mathrm{a}} \sigma T_{\mathrm{a}}^{4}$

for surface temperature $T_{\mathrm{s}}$, near-surface air temperature $T_{\mathrm{a}}$, and atmospheric emissivity $\varepsilon_{\mathrm{a}}$. Terrain emissions (i.e., from the surrounding topography) can also contribute to the incoming longwave radiation, particularly at sites that are adjacent to valley walls.

A spectrally and vertically integrated radiative transfer calculation is needed to predict the incoming longwave radiation from the atmosphere, as this depends on lowertropospheric water vapour, cloud, and temperature profiles. Because the requisite atmospheric data are rarely available in glacial environments, $Q_{\mathrm{L}}^{\downarrow}$ is commonly parameterized at a site as a function of local $(2 \mathrm{~m})$ temperature and humidity. Where available, cloud cover or a proxy for cloud conditions, such as the atmospheric clearness index, are often used to strengthen this parameterization. Hock (2005) and Lhomme et al. (2007) provide reviews of some of the parameterizations of atmospheric emissivity that have been employed in glaciology. We found good results for regressionbased parameterization at two study sites in the Canadian Rocky Mountains (Ebrahimi and Marshall, 2015):

$Q_{\mathrm{L}}^{\downarrow}=\left(a+b e_{\mathrm{v}}+c h\right) \sigma T_{\mathrm{a}}^{4}$

and

$Q_{\mathrm{L}}^{\downarrow}=\left(a+b e_{\mathrm{v}}+c \tau\right) \sigma T_{\mathrm{a}}^{4}$.

Here $a, b$, and $c$ are regression parameters (different in Eqs. 8 and 9), $e_{\mathrm{v}}$ is vapour pressure, $h$ is relative humidity, and $\tau$ is the clearness index, calculated from the ratio of measured to potential direct incoming shortwave radiation.

Solar radiation and cloud data are less commonly available than relative humidity, so Eq. (8) is a slightly less accurate but more portable version of this parameterization (Ebrahimi and Marshall, 2015). Multiple regressions of $\varepsilon_{\mathrm{a}}$ containing both relative humidity and clearness index were rejected, as these are highly (negatively) correlated. All-sky longwave parameterizations using either of these variables are reasonable, with root mean square errors in mean daily incoming longwave radiation of about $10 \mathrm{~W} \mathrm{~m}^{-2}$.

Relative humidity can also be used as a proxy for clearness index if shortwave radiation data are not available. Summer (JJA) observations at Haig Glacier follow the following relation:

$\tau=1.3-0.01 h$,

for mean daily values of $\tau$ and $h\left(R^{2}=0.5\right)$. We draw on this below when we need to estimate perturbations in sky clearness index that are consistent with changes in atmospheric humidity. In accord with the observational basis of Eq. (10), the clearness index is constrained to be within 0.3 and $1(h \in[30,100 \%])$; if daily mean humidity drops below this, we set $\tau=1$.

Turbulent fluxes of sensible and latent energy in the glacier boundary layer are parameterized from a bulk aerodynamic method (e.g., Andreas, 2002):

$Q_{\mathrm{H}}=\rho_{\mathrm{a}} c_{\mathrm{p}} k^{2} v\left[\frac{T_{\mathrm{a}}(z)-T_{\mathrm{S}}}{\ln \left(z / z_{0}\right) \ln \left(z / z_{0_{\mathrm{H}}}\right)}\right]$,

and

$Q_{\mathrm{E}}=\rho_{\mathrm{a}} L_{\mathrm{v}} k^{2} v\left[\frac{q_{\mathrm{a}}(z)-q_{\mathrm{s}}}{\ln \left(z / z_{0}\right) \ln \left(z / z_{0_{\mathrm{E}}}\right)}\right]$.

Here $\rho_{\mathrm{a}}$ is the air density, $c_{\mathrm{p}}$ is the specific heat capacity of air, $L_{\mathrm{v}}$ is the latent heat of evaporation, $k=0.4$ is von Karman's constant, $v$ is wind speed, and $q$ refers to the specific humidity. Measurements of temperature and humidity are assumed to be at two levels, height $z$ (e.g., $2 \mathrm{~m}$ ) and at the surface-air interface, $s$. For a melting glacier surface, $T_{\mathrm{s}}=0^{\circ} \mathrm{C}$, and $q_{\mathrm{s}}$ can be taken from the saturation-specific humidity over ice at temperature $T_{\mathrm{s}}$. We estimate $T_{\mathrm{s}}$ from an inversion of Eq. (6), using measurements of outgoing longwave radiation. In sensitivity tests, where we depart from the observational constraints, $T_{\mathrm{s}}$ is internally modelled within a subsurface snow model (see below), taken from the temperature of the upper snow layer.

Parameters $z_{0}, z_{0_{\mathrm{H}}}$, and $z_{0_{\mathrm{E}}}$ refer to the roughness length scales for turbulent exchange of momentum, heat, and moisture. We adopt fixed values for each, equivalent for both snow and ice $\left(z_{0}=3 \mathrm{~mm} ; z_{0_{\mathrm{H}}}=z_{0_{\mathrm{E}}}=z_{0} / 100\right)$, based on closure of the surface energy balance with reference to observed melt (Marshall, 2014). Atmospheric stability adjustments can be 
introduced in Eqs. (11) and (12) to modify the turbulent flux parameterizations for the stable glacier boundary layer (e.g., Hock and Holmgren, 2005; Giesen et al., 2008). We do not apply stability corrections, as we are able to attain closure in modelled and measured summer melt at this site without this. Others have argued that stability corrections may lead to an underestimation of the turbulent fluxes on mountain glaciers (e.g., Hock and Holmgren, 2005). This may be related to the low-level wind speed maximum that is typical of the glacier boundary layer, which introduces strong turbulence and is not consistent with the logarithmic profile of wind speed that is implicit in Eqs. (11) and (12). It may also be that the effects of atmospheric stability are absorbed in the roughness values - roughness values that are adopted to attain closure in the surface energy balance and melt calculations may be too low, implicitly accounting for the stable boundary layer.

Subsurface temperatures are modelled through a onedimensional multilayer model of heat conduction and meltwater percolation and refreezing in the upper $10 \mathrm{~m}$ of the glacier, the approximate depth of penetration of the annual temperature wave (Cuffey and Paterson, 2010). This depth includes the time-varying seasonal snow layer and the underlying firn or ice. The temperature solution follows

$\rho_{\mathrm{s}} c_{\mathrm{s}} \frac{\partial T}{\partial t}=\frac{\partial}{\partial z}\left(-k_{\mathrm{t}} \frac{\partial T}{\partial z}\right)+\varphi_{\mathrm{t}}$,

where $\rho_{\mathrm{s}}, c_{\mathrm{s}}$, and $k_{\mathrm{t}}$ are the density, heat capacity, and thermal conductivity of the subsurface snow, firn, or ice and $\varphi_{\mathrm{t}}(z)$ is a local source term that accounts for latent heat of refreezing:

$\varphi_{\mathrm{t}}=\rho_{\mathrm{w}} L_{\mathrm{f}} \dot{r} / \Delta z$.

The refreezing rate $\dot{r}$ has units $\mathrm{ms}^{-1}, \varphi_{\mathrm{t}}$ has units $\mathrm{W} \mathrm{m}^{-3}$, and $\Delta z$ is the thickness of the layer in which the meltwater refreezes.

Refreezing is calculated from a hydrological model that is coupled with the subsurface thermal model. We track the volumetric liquid water fraction, $\theta_{\mathrm{w}}$, in the snow/firn pore space; if conductive energy loss occurs in a subsurface layer where liquid water is present, this energy is diverted to latent enthalpy of freezing, rather than cooling the snow. Temperatures cannot drop below $0{ }^{\circ} \mathrm{C}$ until $\theta_{\mathrm{w}}=0$. Liquid water is converted to ice in the subsurface layer.

We model meltwater drainage by assuming that water percolates uniformly, with hydraulic conductivity $k_{\mathrm{h}}$ and neglecting horizontal transport (i.e., assuming only gravitydriven vertical drainage). Local water layer thickness can be expressed $h_{\mathrm{w}}=\theta_{\mathrm{w}} \Delta z$. The local water balance is then

$\frac{\partial h_{\mathrm{w}}}{\partial t}=-k_{\mathrm{h}} \frac{\partial h_{\mathrm{w}}}{\partial z}-\dot{r}$

where the final term accounts for water that is removed through internal refreezing. In principle, this is a source/sink term that could also include internal melting (e.g., from shortwave radiation penetration or percolation of warm rainwater), but we do not consider these processes. We assume an irreducible water content of $3 \%$ for the melting snowpack (Colbeck, 1974), and the maximum volumetric water content is equal to the porosity, $\theta$, although drainage in the seasonal snowpack is efficient and $\theta_{\mathrm{w}}$ is always much less than $\theta$.

\section{Numerical energy balance and subsurface temperature model}

For the energy balance sensitivity experiments in this study, we use a combination of directly observed and modelled glaciometeorological variables. Where we report the directly observed surface energy balance, for the 2002-2012 reference state, we drive the energy balance model with observed 30 min data, including measured albedo and longwave radiation fluxes. Turbulent heat fluxes and subsurface heat conduction are modelled from Eqs. (11) to (15).

Where we do sensitivity tests or run the model with other meteorological input, such as from climate models, we need to allow for internal feedbacks such as freely determined albedo evolution and changes in incoming radiation that will attend changes in atmospheric conditions (e.g., cloud cover, humidity). The energy balance and melt model that we employ is based on daily mean meteorological inputs, in order to make our approach compatible with output from climate models or reanalyses, as well as parameterizations that operate on a daily timescale (Eqs. 8-10). A parameterized diurnal cycle is introduced for temperature and shortwave radiation (see below) in order to capture the effects of overnight refreezing and the fraction of the day that experiences melt (when $Q_{\mathrm{N}}$ and $T_{\mathrm{s}}>0$ ). The model uses a variable time step from $10 \mathrm{~min}$ to $1 \mathrm{~h}$ to allow for stability of the subsurface temperature prognosis.

The subsurface temperature model has 33 layers, with $10 \mathrm{~cm}$ layers until $0.6 \mathrm{~m}$ depth, $20 \mathrm{~cm}$ layers from 0.6 to $2 \mathrm{~m}$, and $40 \mathrm{~cm}$ layers from 2 to $10 \mathrm{~m}$. The upper boundary forcing comes from the conductive heat flux at the snow/iceair interface, $Q_{\mathrm{C}}=-k_{\mathrm{t}} \partial T / \partial z$, modelled from a three-point forward finite-difference approximation of $\partial T / \partial z$. We use a two-step solution, for the temperature (Eq. 13), then the meltwater drainage (Eq. 15). The temperature solution is implicit for the temperature diffusion, with latent heat release from refreezing (the source term in Eq. 13) calculated from the previous time step within the hydrological model. Hydraulic conductivity in Eq. (15) is assigned the value $k_{\mathrm{h}}=10^{-4} \mathrm{~m} \mathrm{~s}^{-1}$, near the low end of estimates reported by Campbell et al. (2006). Meltwater is assumed to drain instantaneously when it reaches the snow-ice interface.

The $10 \mathrm{~m}$ subsurface model consists of the seasonal snowpack of thickness $d_{\mathrm{s}}(t)$, overlying either firn or ice. The grid is fixed with respect to the surface, and each layer is assigned a density, thermal conductivity, and heat capacity according to the medium (snow, firn, or ice). Snow and firn density are modelled as a function of depth and the liquid water and ice 

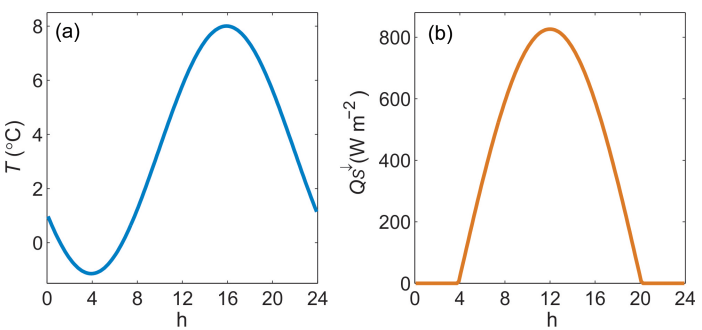

Figure 1. Idealized diurnal cycles of (a) temperature and (b) incoming shortwave radiation used in the energy balance model. These two examples are for a sample day, 1 July 2010, parameterized from daily minimum and maximum temperature in (a) and day of year plus mean daily incident shortwave radiation in (b).

content,

$\rho_{\mathrm{s}}=\rho_{\mathrm{i}}(1-\theta)+\rho_{\mathrm{w}} \theta_{\mathrm{w}}+\rho_{\mathrm{i}} \theta_{\mathrm{i}}$,

for porosity $\theta$, liquid water fraction $\theta_{\mathrm{w}}$, and ice fraction $\theta_{\mathrm{i}}$. Densities $\rho_{\mathrm{s}}, \rho_{\mathrm{i}}$, and $\rho_{\mathrm{w}}$ refer to snow, ice and water, respectively. We prescribe a decrease in porosity with depth following $\theta(z)=0.6-0.05 z$, parameterized to represent the measured summer snow densities at the site $\left(\rho_{\mathrm{s}}=350\right.$ $550 \mathrm{~kg} \mathrm{~m}^{-3}$ ) and give reasonable estimates of firn density, up to $\rho_{\mathrm{s}}=820 \mathrm{~kg} \mathrm{~m}^{-3}$ at $10 \mathrm{~m}$ depth.

Snow accumulates, melts, or undergoes densification on a daily time step, with snow thickness $d$ varying continuously (vs. discretely) within the fixed-grid framework. At depth $d$ below the surface, the grid cell has a weighted combination of thermal properties and densities to reflect the mixture of snow and either firn or ice in that layer. We do not have a model for snow accumulation through the winter months. We treat this simply and linearly accumulate snow from the start of winter until the start of the following melt season, with the accumulation rate set to give a match to the observed May snowpack thickness for each year. These data are available through annual winter mass balance surveys on the glacier, including a snow pit that provides depth and density measurements at the automatic weather station (AWS) site.

The steps in the energy balance and melt model are as follows:

1. Daily mean values are input for temperature, incoming shortwave and longwave radiation, air pressure, specific humidity, wind speed, as well as minimum and maximum temperature.

2. A diurnal temperature cycle is parameterized as a cosine wave with a lag $\tau_{t}=4 \mathrm{~h}$ to give the maximum temperature at 16:00, as per local observations, with an amplitude $A_{t}=\left(T_{\max }-T_{\min }\right) / 2$ (Fig. 1a). For time $t$ (hour of the day) and period $P_{t}=24 \mathrm{~h}$,

$$
T(t)=-A_{t} \cos \left[\frac{2 \pi\left(t-\tau_{t}\right)}{P_{t}}\right] .
$$

3. A diurnal cycle for incoming shortwave radiation is parameterized as a half-cosine wave with a period $P_{\mathrm{sw}}(d)=2 h_{\mathrm{s}}(d)$, where $d$ is the day of year and $h_{\mathrm{s}}$ is the number of hours of sunlight on day $d$ (Fig. 1b). Defining lag $\tau_{\mathrm{sw}}$ and amplitude $A_{\mathrm{sw}}$,

$Q_{\mathrm{s}}^{\downarrow}(t)=\max \left\{-A_{\mathrm{sw}} \cos \left[\frac{2 \pi\left(t-\tau_{\mathrm{sw}}\right)}{P_{\mathrm{sw}}}\right], 0\right\}$.

Sunlight hours are calculated as a function of latitude, $\theta$, and day of year, based on the equation for the sunset hour $h_{\text {ss }}$ (e.g., Liou, 2002):

$\cos \left(h_{\mathrm{ss}}\right)=-\tan (\delta) \tan (\theta)$,

where $\delta$ is the solar declination angle (solar latitude as a function of day of year). Sunlight hours $h_{\mathrm{s}}=2 h_{\mathrm{ss}}$. The lag also varies with the day of year and is calculated by setting peak shortwave radiation to occur at noon: $2 \pi\left(12-\tau_{\mathrm{sw}}\right) / P_{\mathrm{sw}}=\pi$. This gives $\tau_{\mathrm{sw}}=12-h_{\mathrm{s}}$ hours. Amplitude $A_{\mathrm{sw}}$ is calculated by integrating the area under the cosine curve and equating this to the average daily incoming shortwave radiation, $Q_{\mathrm{Sd}}^{\downarrow}$. This gives $A_{\mathrm{sw}}=12 \pi Q_{\mathrm{Sd}}^{\downarrow} / h_{\mathrm{S}} \mathrm{W} \mathrm{m}^{-2}$. This treatment implicitly includes cloud effects that reduce incoming shortwave radiation on a given day (via $Q_{\mathrm{Sd}}^{\downarrow}$ ), but distributed evenly through the day. This neglects any systematic tendency for afternoon vs. morning clouds. For simplicity, we also neglect the effect of zenith angle on atmospheric transmittance (i.e., lower transmittance for larger atmospheric path lengths in the morning and late afternoon), although this could be built into a more refined model.

4. We assume that wind, incoming longwave radiation, air pressure, and specific humidity are constant through the day, held to the mean daily value. For sensitivity tests, $Q_{\mathrm{L}}^{\downarrow}$ is calculated following Eq. (8) and the daily mean value of $Q_{\mathrm{S}}^{\downarrow}$ is perturbed from Eq. (10) and $d Q_{\mathrm{S}}^{\downarrow}=d \tau$.

5. Relative humidity has a diurnal cycle following temperature, assuming constant daily humidity but adjusting $h$ for consistency with the effect of temperature on saturation vapour pressure.

6. Albedo is also modelled on a daily basis for the sensitivity studies. When the seasonal snowpack is melted away, albedo is set to the observed bare-ice value at the site, $\alpha_{i}=0.25$. For fresh or dry snow, a fixed value $\alpha_{0}=0.86$ is used. The snowpack thickness is initialized on 1 May of each year, set to the observed value measured during the annual winter mass balance survey. During the melt season, which is assumed to start after this date, seasonal snow albedo decreases as a function of cumulative positive degree days ( $\sum$ PDD) following Hirose and Marshall (2013):

$\alpha_{\mathrm{s}}(d)=\alpha_{0}-k_{\alpha} \sum \operatorname{PDD}(d)$. 

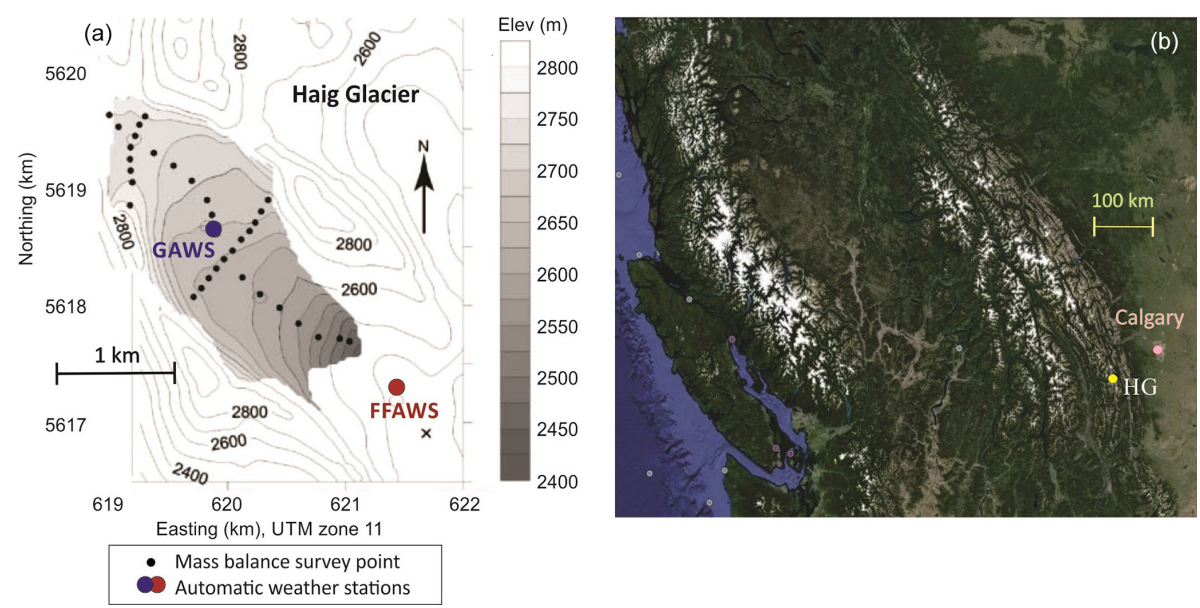

Figure 2. (a) The topography and automatic weather stations on Haig Glacier (GAWS) and the glacier forefield (FFAWS). The smaller black dots are mass balance survey points. (b) The location of Haig Glacier is labelled HG on the Google Earth map of southwestern Canada.

A minimum value of 0.4 is set for old snow. We parameterize the effects of summer snowfall on albedo and mass balance through a stochastic model of summer precipitation events (Marshall, 2014). Precipitation events are set to occur randomly, with 25 events occurring from May through September as the default setting. Precipitation totals vary randomly, between 1 and $10 \mathrm{~mm}$ w.e., with snow at temperatures below $0{ }^{\circ} \mathrm{C}$, rainfall above $2{ }^{\circ} \mathrm{C}$, and rain/snow partitioning increasing linearly over the range $0-2{ }^{\circ} \mathrm{C}$. Following a summer snow event, surface albedo is reset to $\alpha_{0}$, and its albedo begins to decay following Eq. (20). This treatment allows a natural transition to end-of-summer conditions, when fresh snowfall in September or October does not melt away.

7. Subsurface temperatures and the conductive heat flux, $Q_{\mathrm{C}}$, are modelled with $10 \mathrm{~min}$ to $1 \mathrm{~h}$ time steps (chosen for stability of the temperature solution). The updated surface temperature $T_{\mathrm{s}}$ is used for the calculation of outgoing longwave radiation (Eq. 6), sensible heat flux (Eq. 11), and latent heat flux (via $q_{\mathrm{s}}$ in Eq. 12) for the next time step.

8. The hydrology model calculates meltwater drainage and refreezing. Annual meltwater runoff is then the sum of all meltwater that drains, while summer mass balance is equal to the meltwater runoff minus the total summer snowfall, nominally for the period 1 May to 30 September at this site. This allows for some meltwater retention as either liquid water or refrozen ice within the snow or firn. We neglect water storage in the englacial and subglacial hydrology systems.

\section{Field site and observational data}

Reference meteorological conditions, surface energy balance fluxes, and snow conditions are based on in situ measurements at Haig Glacier in the Canadian Rocky Mountains for the period 2002-2012 (Marshall, 2014). Winter mass balance measurements are carried out each May. These observations provide an 11-year record of observed snow depth and summer melt from an AWS located near the median elevation of the glacier, $2660 \mathrm{~m}$ (Fig. 2). This is the upper ablation area of the glacier, which generally undergoes a transition from seasonal snow to exposed glacier ice in August.

Table 1 summarizes the mean observed meteorological and conditions at Haig Glacier over the 11-year reference period. Data coverage is incomplete, particularly in the winter months, as we transitioned to summer only measurements (May-September) after 2009. For the 11 years, data coverage is as follows for most sensors (e.g., temperature, shortwave radiation): JJA - $90 \%$ (909 of 1012 days); MJJAS - $86 \%$ (1441 of 1683 days); annual - 63\% (2519 of 4018 days). There are more missing longwave radiation data, as the sensor was not installed until July 2003. The corresponding numbers are JJA - 76\%; MJJAS - $70 \%$; annual - $46 \%$.

Missing data are gap-filled from a weather station that has operated continuously in the glacier forefield since 2001, at an elevation of $2325 \mathrm{~m}$. The forefield AWS has more complete data coverage than the glacier AWS, above $90 \%$ for all variables. Observational data are used to adjust for the altitudinal and environmental differences between the sites, through either a monthly offset (e.g., $T_{\mathrm{G}}=T_{\mathrm{FF}}-\Delta T$ ) or a scaling factor $\beta$ (e.g., $v_{\mathrm{G}}=\beta_{\mathrm{v}} v_{\mathrm{FF}}$ ). Here, subscripts $\mathrm{G}_{\mathrm{G}}$ and $\mathrm{FF}$ refer to the glacier and forefield AWS sites. The monthly factors are calculated from the set of all available overlapping data for the two stations. The temperature offset approach is equivalent to a lapse rate or can be expressed that way for distributed modelling over the glacier. In this study we con- 
Table 1. Mean monthly weather conditions \pm 1 SD (standard deviation) at Haig Glacier, Canadian Rocky Mountains, May to September 2002-2012. Data are from automatic weather station measurements at an elevation of $2660 \mathrm{~m}$, in the upper ablation zone of the glacier.

\begin{tabular}{lrrrccc}
\hline Month & $T\left({ }^{\circ} \mathrm{C}\right)$ & $h(\%)$ & $e_{\mathrm{v}}(\mathrm{hPa})$ & $q_{\mathrm{v}}\left(\mathrm{g} \mathrm{kg}^{-1}\right)$ & $P(\mathrm{hPa})$ & $v\left(\mathrm{~m} \mathrm{~s}^{-1}\right)$ \\
\hline May & $-1.4 \pm 1.1$ & $73 \pm 4$ & $4.0 \pm 0.4$ & $3.4 \pm 0.4$ & $743.0 \pm 2.4$ & $2.8 \pm 0.2$ \\
June & $2.6 \pm 0.9$ & $73 \pm 6$ & $5.5 \pm 0.5$ & $4.6 \pm 0.4$ & $748.1 \pm 1.4$ & $2.6 \pm 0.2$ \\
July & $6.9 \pm 1.4$ & $62 \pm 5$ & $6.4 \pm 0.4$ & $5.3 \pm 0.3$ & $751.2 \pm 1.6$ & $2.8 \pm 0.3$ \\
August & $5.9 \pm 1.1$ & $64 \pm 7$ & $6.1 \pm 0.4$ & $5.1 \pm 0.4$ & $750.8 \pm 1.4$ & $2.5 \pm 0.2$ \\
September & $2.1 \pm 1.8$ & $71 \pm 10$ & $5.0 \pm 0.4$ & $4.2 \pm 0.3$ & $748.4 \pm 1.8$ & $3.0 \pm 0.4$ \\
\hline JJA & $5.1 \pm 0.8$ & $67 \pm 4$ & $5.7 \pm 0.4$ & $4.8 \pm 0.3$ & $750.0 \pm 1.1$ & $2.6 \pm 0.2$ \\
MJJAS & $3.2 \pm 0.7$ & $69 \pm 4$ & $5.3 \pm 0.3$ & $4.3 \pm 0.3$ & $748.3 \pm 1.4$ & $2.7 \pm 0.2$ \\
\hline
\end{tabular}
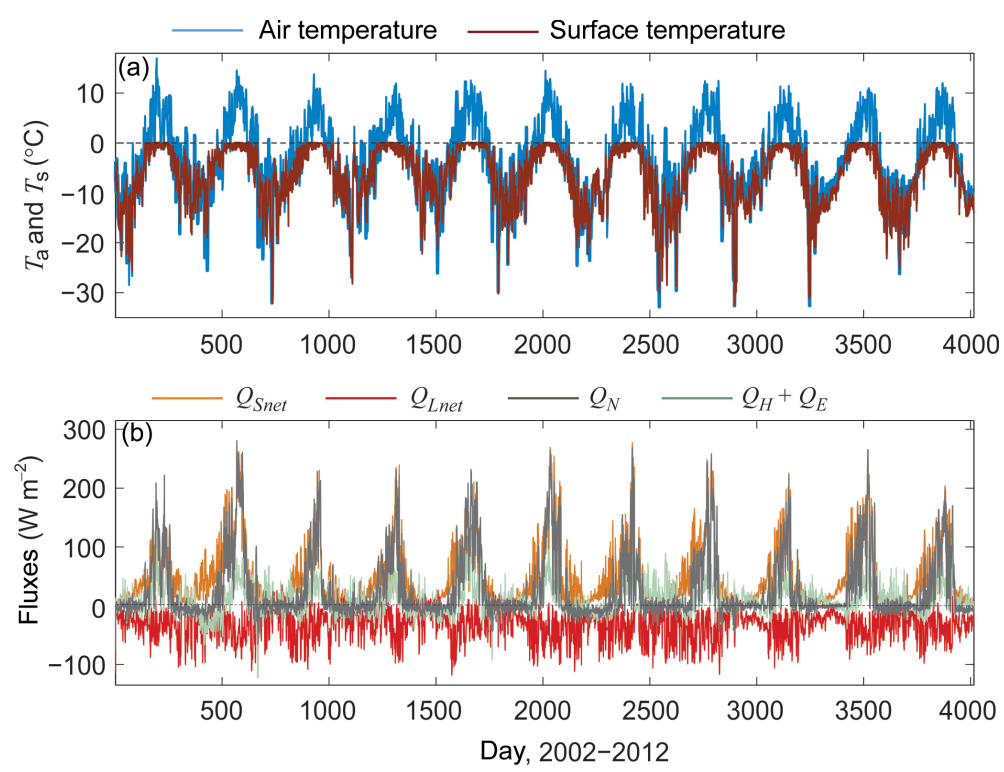

Figure 3. The 11-year record of (a) air temperature, modelled surface temperature, and (b) surface energy fluxes at the Haig Glacier AWS site. Daily mean values are plotted from 1 January 2002 to 31 December 2012.

sider only the point energy balance at the glacier AWS site. If both stations are missing data, gap-filling is done through assignment of mean daily observational data.

To give a sense of the complete data record, Fig. 3 shows examples of the full record, for air temperature, modelled surface temperature, and the energy fluxes. Average June to August (JJA) air and surface temperature are 5.1 and $-0.6^{\circ} \mathrm{C}$, respectively, and $98 \%$ of JJA days reach surface temperatures of $0^{\circ} \mathrm{C}$ (melting conditions) in the 11-year record. The surface energy fluxes in Fig. $3 b$ illustrate the dominance of net radiation in governing net energy at this site (Table 2).

Mean daily values for the 11-year record are plotted in Fig. 4. As is typical for midlatitude glaciers, net radiation is the main energy flux that drives glacier melt at this site (Fig. 4c). Net radiation is negative in the winter, when shortwave inputs are low, albedo is high, and longwave cooling gives a radiation deficit. Net radiation is positive in the summer and increases through the melt season. This is driven by increases in net shortwave radiation as snow albedo declines at the site and then melts away to expose the underlying glacier ice (Fig. 4a). Measurements at the AWS site indicate a seasonal snow albedo decrease from about 0.8 to about 0.4 each summer, which may be due to a combination of increased snow-water content, grain metamorphosis in the temperate snowpack, and increasing concentration of impurities through the melt season (e.g., Cuffey and Paterson, 2010).

Median daily melt rates for the period 2002-2012 are plotted in Fig. 4d, along with the interquartile range. On average, $65 \%$ of the annual glacier melt occurs in the months of July and August. Net energy peaks in August, when the lowalbedo glacier ice is exposed. Sensible heat flux peaks in July and is the other main source of energy contributing to glacier melt. On average for JJA, net radiation and sensible heat flux constitute 70 and $30 \%$ of the net energy, respectively. Latent heat flux represents a small sink of energy, and conductive heat flux is a minor source of energy. 
Table 2. Mean monthly surface energy balance terms \pm 1 SD at Haig Glacier, Canadian Rocky Mountains, May to September 2002-2012. Radiation fluxes and albedo values are from automatic weather station measurements and the turbulent fluxes and subsurface heat conduction are modelled from the AWS data. Fluxes are in $\mathrm{W} \mathrm{m}^{-2}$ and melt totals are in $\mathrm{m}$ w.e.

\begin{tabular}{lccrcrrrrc}
\hline Month & $Q_{\mathrm{S}}^{\downarrow}$ & $\alpha_{\mathrm{S}}$ & $Q_{\mathrm{L}}^{\downarrow}$ & $Q_{\mathrm{L}}^{\uparrow}$ & $Q_{\mathrm{H}}$ & $Q_{\mathrm{E}}$ & $Q_{\mathrm{C}}$ & $Q_{\mathrm{N}}$ & melt \\
\hline May & $249 \pm 24$ & $0.76 \pm 0.04$ & $258 \pm 12$ & $299 \pm 4$ & $7 \pm 4$ & $-11 \pm 3$ & $5 \pm 2$ & $22 \pm 12$ & $0.20 \pm 0.10$ \\
June & $237 \pm 23$ & $0.70 \pm 0.05$ & $276 \pm 14$ & $310 \pm 2$ & $17 \pm 4$ & $-5 \pm 4$ & $3 \pm 1$ & $56 \pm 21$ & $0.45 \pm 0.16$ \\
July & $240 \pm 19$ & $0.57 \pm 0.06$ & $275 \pm 8$ & $313 \pm 1$ & $38 \pm 9$ & $1 \pm 5$ & $1 \pm 1$ & $109 \pm 27$ & $0.88 \pm 0.21$ \\
August & $205 \pm 25$ & $0.38 \pm 0.07$ & $273 \pm 11$ & $312 \pm 1$ & $32 \pm 7$ & $-1 \pm 3$ & $2 \pm 1$ & $123 \pm 22$ & $0.99 \pm 0.18$ \\
September & $140 \pm 30$ & $0.59 \pm 0.09$ & $271 \pm 13$ & $306 \pm 3$ & $23 \pm 12$ & $-6 \pm 3$ & $3 \pm 2$ & $42 \pm 21$ & $0.34 \pm 0.16$ \\
\hline JJA & $227 \pm 14$ & $0.55 \pm 0.06$ & $275 \pm 6$ & $312 \pm 1$ & $29 \pm 3$ & $-2 \pm 3$ & $2 \pm 1$ & $97 \pm 19$ & $2.32 \pm 0.45$ \\
MJJAS & $215 \pm 17$ & $0.60 \pm 0.04$ & $271 \pm 7$ & $308 \pm 1$ & $23 \pm 4$ & $-4 \pm 3$ & $3 \pm 1$ & $71 \pm 15$ & $2.86 \pm 0.59$ \\
\hline
\end{tabular}
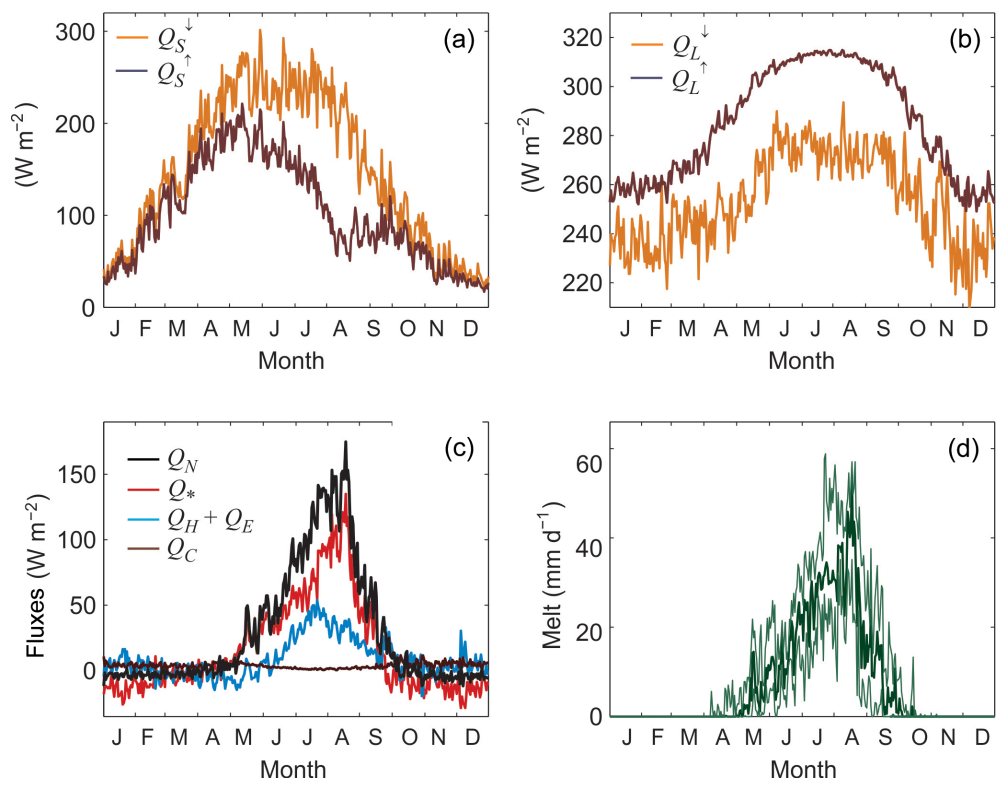

Figure 4. The average annual cycle of (a-c) surface energy fluxes and (d) daily melt at the Haig Glacier AWS. Daily mean values are plotted for the period 2002-2012. For melt rates, the heavy line is the median value and the thin lines indicate the interquartile range.

The energy balance and snowpack models have been developed and tested elsewhere (Marshall, 2014; Ebrahimi and Marshall, 2015), so we do not present the model validation in detail here. Comparisons are favourable between AWS observations (e.g., in situ albedo, SR50-inferred melt), the model driven with 30 min AWS data, and the "daily" version of the model used here, which includes parameterizations of albedo, incoming longwave radiation, and the diurnal temperature and shortwave radiation cycles (Sect. 2). The simplified daily model loses some reality, but its overall performance is excellent.

As an example, glacier AWS data from summer 2015 are used as an independent test of the model, with its default parameterizations. Observed melt at the AWS site was $3.1 \pm 0.1 \mathrm{~m}$ w.e. in summer 2015 , while the melt model forced by $30 \mathrm{~min}$ AWS data gives $3.04 \mathrm{~m}$ w.e. and the parameterized, daily version of the model gives $2.98 \mathrm{~m}$ w.e. Taking the 30 min AWS-driven results as the reference, the root mean square error in the daily melt predictions for the parameterized model is $3 \%$ ( $0.7 \mathrm{~mm}$ w.e., relative to a daily mean value of $22.7 \mathrm{~mm}$ w.e.). Departures from the observations are primarily associated with the albedo, which is overestimated in summer 2015. Overall the parameterized daily model has good skill and is an appropriate tool for the sensitivity analyses presented here.

\section{Theoretical sensitivity of the surface energy balance}

Surface energy balance processes and summer melt rates depend on various meteorological influences (Eqs. 4-12). Warm summers generally cause high melt rates and promote negative mass balance, but the energy balance is sensitive to other weather conditions as well. To examine these sensitivities, meteorological variables in Tables 1 and 2 can be perturbed one at a time or in combination to examine the impact 
on summer melt at the Haig Glacier AWS site. Perturbations are introduced with respect to the mean JJA meteorological conditions from 2002 to 2012.

Theoretical sensitivities are calculated in this section by differentiating the net energy balance with respect to each meteorological variable. This is akin to generating a Jacobian matrix for $Q_{\mathrm{N}}$, based on partial derivatives of the dependent variables in the surface energy balance. One cannot gauge the most important meteorological influence on surface energy and mass balance from the sensitivities to a unit change in each variable. For instance, a change in specific humidity of $1 \mathrm{~g} \mathrm{~kg}^{-1}$ equals $3.3 \mathrm{SD}$ (standard deviations), with respect to the interannual (JJA) variability (Table 1). In contrast, summer temperature has a standard deviation of $0.8^{\circ} \mathrm{C}$, so a $1^{\circ} \mathrm{C}$ temperature change is a smaller perturbation. To allow a direct comparison of the theoretical sensitivities and to give a simple representation of their natural, interannual variability, we perturb each variable by $1 \mathrm{SD}$, based on the values reported in Tables 1 and 2.

We consider the core summer months, JJA, to calculate the theoretical sensitivity because the glacier surface is at melting point for most of this time (Fig. 3a), which is a necessary condition to relate net energy to melt. More than $80 \%$ of the annual melt also occurs in this season (Table 2 and Fig. 4d), so meteorological forcing over this period has the highest impact on glacier melt.

\subsection{Sensitivity to temperature}

Air temperature appears directly in the expressions for $Q_{\mathrm{L}}^{\downarrow}$ and $Q_{\mathrm{H}}$. Temperature change may also influence the surface energy balance through influences on other variables, such as atmospheric moisture $\left(Q_{\mathrm{E}}\right)$. For a melting glacier surface, where surface and subsurface temperatures are at $0{ }^{\circ} \mathrm{C}$, air temperature changes do not directly influence $Q_{\mathrm{L}}^{\uparrow}$ or $Q_{\mathrm{C}}$. To estimate the magnitude of temperature sensitivity, we differentiate each energy balance flux with respect to temperature.

For incoming longwave radiation, Eq. (7), the resulting temperature sensitivity is

$$
\frac{\partial Q_{\mathrm{L}}^{\downarrow}}{\partial T}=4 \sigma \varepsilon_{\mathrm{a}} T_{\mathrm{a}}^{3}+\sigma T_{\mathrm{a}}^{4} \frac{\partial \varepsilon_{\mathrm{a}}}{\partial T} .
$$

This general form applies to a range of formulations for $\varepsilon_{\mathrm{a}}$, such as those of Brutsaert (1975), Lhomme et al. (2007), or Sedlar and Hock (2009). Adopting the parameterization in Eq. (8), which performs well at Haig Glacier, results in

$$
\frac{\partial Q_{\mathrm{L}}^{\downarrow}}{\partial T}=4 \sigma \varepsilon_{\mathrm{a}} T_{\mathrm{a}}^{3}+\sigma T_{\mathrm{a}}^{4}\left(b \frac{\partial e_{\mathrm{v}}}{\partial T}+c \frac{\partial h}{\partial T}\right) .
$$

The last two terms reflect potential feedbacks of temperature change on humidity. While we are only considering perturbations to temperature in this section, vapour pressure and relative humidity cannot both remain constant under a temperature change. We first assume that relative humidity $h$ remains constant, under which conditions we assume that cloud cover and sky clearness will be unchanged. For constant $h, e_{\mathrm{v}}$ scales with temperature following the ClausiusClapeyon relation for saturation vapour pressure:

$\frac{\partial e_{\mathrm{v}}}{\partial T}=\frac{h}{100} \frac{\partial e_{\mathrm{s}}}{\partial T}=\frac{h}{100}\left(\frac{L_{\mathrm{v}} e_{\mathrm{s}}}{R_{\mathrm{v}} T_{\mathrm{a}}^{2}}\right)=\frac{L_{\mathrm{v}} e_{\mathrm{v}}}{R_{\mathrm{v}} T_{\mathrm{a}}^{2}}$,

where $R_{\mathrm{V}}=461.5 \mathrm{~J} \mathrm{~kg}^{-1}{ }^{\circ} \mathrm{C}^{-1} \mathrm{i}$ s the gas-law constant for water vapour.

For the mean JJA meteorological conditions at Haig Glacier, Eqs. (22) and (23) give $\partial Q_{\mathrm{L}}^{\downarrow} / \partial T=4.7 \mathrm{~W} \mathrm{~m}^{-2}{ }^{\circ} \mathrm{C}^{-1}$. Temperature increases affect $Q_{\mathrm{L}}^{\downarrow}$ through both the direct effect of higher emission temperatures and the indirect effect of higher atmospheric emissivity, with these two terms in Eq. (21) contributing 4.0 and $0.7 \mathrm{~W} \mathrm{~m}^{-2}{ }^{\circ} \mathrm{C}^{-1}$, respectively.

The temperature sensitivity of sensible and latent heat fluxes follow

$\frac{\partial Q_{\mathrm{H}}}{\partial T}=\frac{\rho_{\mathrm{a}} c_{\mathrm{p}} k^{2} v}{\ln \left(z / z_{0}\right) \ln \left(z / z_{0_{\mathrm{H}}}\right)}$

and

$\frac{\partial Q_{\mathrm{E}}}{\partial T}=\frac{\rho_{\mathrm{a}} L_{\mathrm{p}} k^{2} v}{\ln \left(z / z_{0}\right) \ln \left(z / z_{0_{\mathrm{E}}}\right)}\left(\frac{\partial q_{\mathrm{v}}}{\partial T}\right)$,

where

$\frac{\partial q_{\mathrm{v}}}{\partial T} \approx \frac{R_{\mathrm{d}}}{P R_{\mathrm{v}}}\left(\frac{\partial e_{\mathrm{v}}}{\partial T}\right)$

for the dry gas-law constant $R_{\mathrm{d}}=289 \mathrm{~J} \mathrm{~kg}^{-1}{ }^{\circ} \mathrm{C}^{-1}$ and air pressure $P$, under the assumption that air pressure and density are constant for small changes in temperature. Table 3 gives the turbulent flux sensitivities for mean JJA conditions at Haig Glacier. Perturbations to both $Q_{\mathrm{H}}$ and $Q_{\mathrm{E}}$ are positive with an increase in temperature and the assumption of constant $h$. In combination with the increase in $Q_{\mathrm{L}}^{\downarrow}$, net energy over the summer months is augmented by $12 \mathrm{~W} \mathrm{~m}^{-2}$ for a $1^{\circ} \mathrm{C}$ increase in temperature. Interannual variations in summer temperature $(1 \sigma)$ equal $0.8^{\circ} \mathrm{C}$, giving a net energy perturbation $\delta Q_{\mathrm{N} \sigma}=+10 \mathrm{~W} \mathrm{~m}^{-2}$ (Table 3).

Fluctuations in energy balance can be related to melt rates through their combined influence on $Q_{\mathrm{N}}$, with $\delta \dot{m}=\delta Q_{\mathrm{N}} / \rho_{\mathrm{W}} L_{\mathrm{f}}$. Table 3 summarizes these impacts on summer melt, assuming a JJA melt season (92 days). The $1 \sigma$ temperature increase $\left(\delta Q_{\mathrm{N} \sigma}=10 \mathrm{~W} \mathrm{~m}^{-2}\right)$ is equivalent to $236 \mathrm{~mm}$ of meltwater at the AWS site, a $10 \%$ increase over the reference JJA melt, $2320 \mathrm{~mm}$ w.e. These are the direct impacts of higher temperatures, not accounting for feedbacks or nonlinearity in the seasonal evolution of melt conditions. These calculations assume that melting conditions prevail throughout the summer and all of this energy can be directed to snow/ice melt, which is not strictly true. We include them because estimates of the potential influence on summer 
Table 3. Surface energy balance sensitivity to meteorological perturbations over a melting glacier surface, from direct feedbacks only. Calculations are for mean JJA conditions at Haig Glacier. All energy flux perturbations are expressed in $\mathrm{W} \mathrm{m}^{-2}$. $\delta Q_{\mathrm{N} \sigma}$ is the net energy perturbation for a $1 \sigma$ increase in the variable. The melt perturbation, $\delta m_{\sigma}$, has units of $\mathrm{mm}$ w.e. and is calculated assuming that $\delta Q_{\mathrm{N} \sigma}$ holds for JJA (92 days).

\begin{tabular}{lrrrrrrrrr}
\hline Perturbation & $\delta Q_{\mathrm{S}}^{\downarrow}$ & $\delta \alpha$ & $\delta Q_{\mathrm{S}}^{\text {net }}$ & $\delta Q_{\mathrm{L}}^{\downarrow}$ & $\delta Q_{\mathrm{H}}$ & $\delta Q_{\mathrm{E}}$ & $\delta Q_{\mathrm{N}}$ & $\delta Q_{\mathrm{N} \sigma}$ & $\delta m_{\sigma}$ \\
\hline$\delta T=1^{\circ} \mathrm{C} ; \delta h=0$ & 0 & 0 & 0 & 4.7 & 4.2 & 3.5 & 12.4 & 9.9 & 236 \\
$\delta T=1^{\circ} \mathrm{C} ; \delta q_{\mathrm{v}}=\delta \tau=\delta \varepsilon_{\mathrm{a}}=0$ & 0 & 0 & 0 & 4.0 & 4.2 & 0 & 8.3 & 6.6 & 157 \\
$\delta T=1^{\circ} \mathrm{C} ; \delta q_{\mathrm{v}}=0 ; \delta \tau, \delta \varepsilon_{\mathrm{a}}$ & 22.6 & 0 & 10.2 & -7.8 & 4.20 & 6.6 & 5.3 & 125 & \\
$\delta q_{\mathrm{v}}=1 \mathrm{~g} \mathrm{~kg}^{-1} ; \delta \tau=\delta \varepsilon_{\mathrm{a}}=0$ & 0 & 0 & 0 & 0 & 0 & 10.5 & 10.5 & 3.2 & 76 \\
$\delta q_{\mathrm{v}}=1 \mathrm{~g} \mathrm{~kg}^{-1} ; \delta \tau, \delta \varepsilon_{\mathrm{a}}$ & -41.8 & 0 & -18.8 & 24.1 & 0 & 10.5 & 15.7 & 4.7 & 112 \\
$\delta v=1 \mathrm{~m} \mathrm{~s}^{-1}$ & 0 & 0 & 0 & 0 & 8.3 & -1.4 & 6.9 & 2.1 & 50 \\
$\delta Q_{0}=1 \mathrm{~W} \mathrm{~m}^{-2}$ & 0.6 & 0 & 0.3 & 0 & 0 & 0 & 0.3 & - & - \\
$\delta Q_{\mathrm{S}}^{\downarrow}=10 \mathrm{~W} \mathrm{~m}^{-2}$ & 10.0 & 0 & 4.5 & 0 & 0 & 0 & 4.5 & 6.3 & 150 \\
$\delta Q_{\mathrm{L}}^{\downarrow}=10 \mathrm{~W} \mathrm{~m}^{-2}$ & 0 & 0 & 0 & 10 & 0 & 0 & 10.0 & 6.0 & 143 \\
$\delta \tau=0.1$ & 36.0 & 0 & 16.2 & -19.6 & 0 & -4.6 & -8.0 & -3.2 & -76 \\
$\delta \alpha_{\mathrm{S}}=0.1$ & 0 & 0.1 & -22.7 & 0 & 0 & 0 & -22.7 & -13.6 & -323 \\
\hline
\end{tabular}

melt provide an intuitive way to understand and compare sensitivities. We consider more realistic relations between net energy and melt in the modelled sensitivities of Sect. 5.

This initial scenario assumes that the warmer atmosphere contains more moisture, which is not necessarily the case. For instance, high summer temperatures in this region are commonly associated with ridging and subsidence, i.e., hot, dry conditions. If we assume that $q_{\mathrm{v}}$ is invariant with temperature (case 2 in Table 3), there is no feedback on the latent heat flux and the increase in net energy is less than with constant $h: \delta Q_{\mathrm{N} \sigma}=6.6 \mathrm{~W} \mathrm{~m}^{-2}$ and $\delta m_{\sigma}=157 \mathrm{~mm}$ w.e.

However, there are additional feedbacks associated with relative humidity. If $q_{\mathrm{v}}$ is invariant, relative humidity must change to be consistent with the temperature perturbation. As an example, an increase of $1{ }^{\circ} \mathrm{C}$ with no change in $q_{\mathrm{v}}$ corresponds to a decrease of $6 \%$ in mean summer $h$ at our site, to $61 \%$. This lowers the atmospheric emissivity in Eq. (8), reduces the incoming longwave radiation, and impacts $\partial \varepsilon_{\mathrm{a}} / \partial T$ in Eq. (22). To be internally consistent, reduced humidity anomalies should also be associated with changes in cloud cover. For the $1{ }^{\circ} \mathrm{C}$ temperature increase, the $6 \%$ decrease in relative humidity corresponds to an increase in clearness index of 0.06 (Eq. 10) from 0.63 to 0.69 .

The effects of these radiation feedbacks are given in Table 3. Reduced relative humidity decreases $Q_{\mathrm{L}}^{\downarrow}$ and increases $Q_{\mathrm{S}}^{\downarrow}$. The resulting increase in shortwave radiation partially offsets the decline in $Q_{\mathrm{L}}^{\downarrow}$, but there is an overall reduction in net radiation. For our parameterizations of the incoming radiation fluxes as a function of humidity, the effect of drier air on longwave radiation is stronger than the shortwave radiation feedback. This reduces the overall sensitivity to temperature change relative to the first two cases, with $\delta Q_{\mathrm{N} \sigma}=5.3 \mathrm{~W} \mathrm{~m}^{-2}$ and $\delta m_{\sigma}=125 \mathrm{~mm}$ w.e. Note that these temperature scenarios are all idealized, neglecting albedo feedbacks and other indirect effects of a temperature change. These feedbacks are assessed in Sect. 5.

\subsection{Sensitivity to humidity and wind}

Similar derivatives and energy balance sensitivities can be derived with respect to the other meteorological variables to explore the sensitivity of summer melt to different weather conditions. The sensitivity of sensible and latent heat fluxes to wind perturbations follow

$$
\frac{\partial Q_{\mathrm{H}}}{\partial v}=\frac{\rho_{\mathrm{a}} c_{\mathrm{p}} k^{2}\left(T_{\mathrm{a}}-T_{\mathrm{s}}\right)}{\ln \left(z / z_{0}\right) \ln \left(z / z_{0_{\mathrm{H}}}\right)}
$$

and

$$
\frac{\partial Q_{\mathrm{E}}}{\partial v}=\frac{\rho_{\mathrm{a}} L_{\mathrm{p}} k^{2}\left(q_{\mathrm{v}}-q_{\mathrm{s}}\right)}{\ln \left(z / z_{0}\right) \ln \left(z / z_{0_{\mathrm{E}}}\right)},
$$

while the sensitivity to humidity is

$$
\frac{\partial Q_{\mathrm{E}}}{\partial q_{\mathrm{v}}}=\frac{\rho_{\mathrm{a}} L_{\mathrm{p}} k^{2} v}{\ln \left(z / z_{0}\right) \ln \left(z / z_{0_{\mathrm{E}}}\right)} .
$$

Incoming longwave radiation is also affected by perturbations in humidity, following

$$
\frac{\partial Q_{\mathrm{L}}^{\downarrow}}{\partial q_{\mathrm{v}}}=\sigma T_{\mathrm{a}}^{4} \frac{\partial \varepsilon_{\mathrm{a}}}{\partial q_{\mathrm{v}}}=\sigma T_{\mathrm{a}}^{4}\left(b \frac{\partial e_{\mathrm{v}}}{\partial q_{\mathrm{v}}}+c \frac{\partial h}{\partial q_{\mathrm{v}}}\right) .
$$

Table 3 summaries the theoretical sensitivities for specific humidity and wind perturbations of $1 \mathrm{~g} \mathrm{~kg}^{-1}$ and $1 \mathrm{~m} \mathrm{~s}^{-1}$, respectively, assuming that temperature is unchanged. For the humidity, we present two scenarios: the first with perturbations to only the specific and relative humidity and the second including the expected effects of an increase in relative humidity on cloud cover. 
Changes in humidity directly impact the latent heat flux and may also influence incoming longwave radiation and cloud cover (hence, incoming shortwave radiation). We consider the effects of a humidity perturbation with and without radiative feedbacks in Table 3 . For $\delta q_{\mathrm{v}}=1 \mathrm{~g} \mathrm{~kg}^{-1}$ and fixed temperature, mean summer relative humidity increases by 12 , to $79 \%$, and $Q_{\mathrm{E}}$ and $Q_{\mathrm{N}}$ increase by $10.5 \mathrm{~W} \mathrm{~m}^{-2}$. Interannual variations in $q_{\mathrm{v}}$ equal $0.3 \mathrm{~g} \mathrm{~kg}^{-1}$, giving $\delta Q_{\mathrm{N} \sigma}=3.2 \mathrm{~W} \mathrm{~m}^{-2}$, corresponding to a $76 \mathrm{~mm}(3 \%)$ increase in summer melt.

Where radiation feedbacks are included, the increases in specific and relative humidity have a strong influence on the atmospheric emissivity in Eq. (8), giving an increase in $Q_{\mathrm{L}}^{\downarrow}$ of $24 \mathrm{~W} \mathrm{~m}^{-2}$. This is partially offset by cloud feedbacks associated with the increased humidity. Following Eq. (10), $\delta h=12 \%$ equates to a decrease in atmospheric transmissivity of 0.11 , which strongly attenuates incoming shortwave radiation. This reduces the net radiation by $19 \mathrm{~W} \mathrm{~m}^{-2}$, but the radiation feedbacks remain positive. The net impact of a $1 \sigma$ humidity perturbation $\delta q_{\mathrm{v}}=0.3 \mathrm{~g} \mathrm{~kg}^{-1}$ is then $4.7 \mathrm{~W} \mathrm{~m}^{-2}$, corresponding to a $112 \mathrm{~mm}(5 \%)$ increase in summer melt.

Wind perturbations have straightforward linear effects on $Q_{\mathrm{H}}$ and $Q_{\mathrm{E}}$, giving a net sensitivity $\partial Q_{\mathrm{N}} / \partial v=+7 \mathrm{~W} \mathrm{~m}^{-2}\left(\mathrm{~m} \mathrm{~s}^{-1}\right)^{-1}$. Sensible heat flux increases and evaporative cooling decreases slightly. Winds have a low interannual variability at this site, $0.2 \mathrm{~m} \mathrm{~s}^{-1}$, so the associated net energy anomaly is $\delta Q_{\mathrm{N} \sigma}=2 \mathrm{~W} \mathrm{~m}^{-2}$, equivalent to $50 \mathrm{~mm}$ w.e. in summer melt.

\subsection{Sensitivity to the radiation fluxes}

Net shortwave radiation is affected by variations in top-ofatmosphere insolation, the clearness index (i.e., cloud conditions), and surface albedo. Our functional relationship for net shortwave radiation is $Q_{S_{\text {net }}}=Q_{\mathrm{S}}^{\downarrow}\left(1-\alpha_{\mathrm{S}}\right)=Q_{S_{\varphi}} \tau\left(1-\alpha_{\mathrm{S}}\right)$, for potential direct insolation $Q_{S_{\varphi}}$ and clearness index $\tau$. From Eq. (4), sensitivity to top-of-atmosphere insolation $Q_{0}$ follows

$$
\frac{\partial Q_{S_{\mathrm{net}}}}{\partial Q_{0}}=\tau\left(1-\alpha_{\mathrm{S}}\right) \cos (Z) \varphi_{0}^{P / P_{0} \cos (Z)} \text {. }
$$

An anomaly of $1 \mathrm{~W} \mathrm{~m}^{-2}$ in the top-of-atmosphere insolation, $Q_{0}$, gives $\delta Q_{\mathrm{S}}^{\downarrow}=0.6 \mathrm{~W} \mathrm{~m}^{-2}$, and the net radiation impact is further reduced to $0.3 \mathrm{~W} \mathrm{~m}^{-2}$ by the surface albedo. The net impact of top-of-atmosphere solar variability, such as sunspot cycles, is therefore small.

In contrast, incoming radiation fluxes and energy balance are strongly sensitive to atmospheric transmissivity, which in turn is largely governed by cloud cover. Direct, independent variations in incoming shortwave and longwave radiation are reported in Table 3 for fluctuations of $10 \mathrm{~W} \mathrm{~m}^{-2}$ and for $1 \sigma$ variations in each. Sensitivity is moderate, of order $6 \%$ of the net energy.

It is more appropriate to consider covariations of these radiation fluxes that can be expected in association with changes in cloud cover. We can estimate through the sky clearness index, $\tau$, as parameterized via Eqs. (9) and (10), which relate the atmospheric emissivity and relative humidity to clearness index. As an example, reduced cloud cover may be associated with a $1 \sigma$ increase in $\tau$ of 0.1 , from 0.63 to 0.73 . This translates to an increase in net shortwave energy of $16 \mathrm{~W} \mathrm{~m}^{-2}$ (Table 3 ), but the change in cloud cover also impacts incoming longwave radiation. Clearer skies in the example of Table 3 give lower $h$, lower $e_{\mathrm{v}}$, and lower $Q_{\mathrm{L}}^{\downarrow}$. Latent heat flux also declines. The overall result is a reduction in net energy for an increase in $\tau$. A $1 \sigma$ increase $(+0.04)$ gives a $3 \%$ reduction in net energy.

\subsection{Sensitivity to albedo}

The sensitivity to albedo changes is comparatively high. An change in albedo of 0.1 creates an energy balance perturbation of more than $100 \mathrm{~W} \mathrm{~m}^{-2}$ at local noon in mid-summer. The magnitude of this effect varies with latitude, time of year, and atmospheric transmissivity. Integrated over the daily solar path and over the summer, an albedo increase of 0.1 reduces net solar radiation by $-23 \mathrm{~W} \mathrm{~m}^{-2}$. Measurements at the site indicate an interannual albedo variability of 0.06 , equivalent to $14 \%$ of the net energy or $\delta m_{\sigma}=-323 \mathrm{~mm}$ w.e.

\subsection{Summary}

Overall, the results indicate a strong sensitivity of the summer energy balance and melt to temperature and albedo, with weaker influences from cloud conditions, humidity, and wind speed.

These theoretical sensitivities are idealized, however, and neglect many important feedbacks and glaciometeorological interactions that occur in glacier environments. The next two sections examine the energy balance sensitivity at Haig Glacier within an energy-balance melt model. This allows an estimate of feedbacks associated with the evolution of albedo, interannual variability in weather conditions, and meteorologically consistent covariance of weather variables.

\section{Modelled sensitivity of the surface energy balance}

We use a point model of surface energy balance, described in detail in Sect. 2. For all numerical experiments described below, we use the daily model with parameterizations of the longwave radiation fluxes, atmospheric clearness, diurnal cycles of temperature and shortwave radiation, and surface albedo evolution, following Eqs. (6), (8), (10), (17), (18), and (20). Surface temperature is modelled from the subsurface temperature model. The mean daily forcing for the energy balance and snowpack models is taken from the glacier AWS data, and the model is run year-round for the period 2002-2012. The 1 May snowpack thickness (winter accumulation) is specified for each year based on the measured winter mass balance at the AWS site. 
Table 4. Net energy balance sensitivity to meteorological perturbations in the surface energy balance model, based on regressions to the sensitivity curves (cf. Fig. 6). Also shown is the change in net energy associated with a $1 \sigma$ increase in each parameter, averaged over JJA.

\begin{tabular}{llr}
\hline Perturbation & Sensitivity & $\delta Q_{\mathrm{N}}$ for $+1 \sigma$ \\
\hline $1 . \delta T= \pm 2{ }^{\circ} \mathrm{C} ; \delta h=0 ; \delta \alpha_{\mathrm{S}}=0$ & $\partial Q_{\mathrm{N}} / \partial T=13 \mathrm{~W} \mathrm{~m}^{-2}\left({ }^{\circ} \mathrm{C}\right)^{-1}$ & $+10 \mathrm{~W} \mathrm{~m}^{-2}$ \\
2. $\delta T= \pm 2{ }^{\circ} \mathrm{C} ; \delta h=0$ & $\partial Q_{\mathrm{N}} / \partial T=27 \mathrm{~W} \mathrm{~m}^{-2}\left({ }^{\circ} \mathrm{C}\right)^{-1}$ & $+21 \mathrm{~W} \mathrm{~m}^{-2}$ \\
$3 . \delta T= \pm 2{ }^{\circ} \mathrm{C} ; \delta q_{\mathrm{v}}=\delta \tau=\delta \varepsilon_{\mathrm{a}}=0$ & $\partial Q_{\mathrm{N}} / \partial T=21 \mathrm{~W} \mathrm{~m}^{-2}\left({ }^{\circ} \mathrm{C}\right)^{-1}$ & $+17 \mathrm{~W} \mathrm{~m}^{-2}$ \\
4. $\delta T= \pm 2{ }^{\circ} \mathrm{C} ; \delta q_{\mathrm{v}}=0 ; \delta \tau, \delta \varepsilon_{\mathrm{a}}$ & $\partial Q_{\mathrm{N}} / \partial T=17 \mathrm{~W} \mathrm{~m}^{-2}\left({ }^{\circ} \mathrm{C}\right)^{-1}$ & $+13 \mathrm{~W} \mathrm{~m}^{-2}$ \\
$5 . \delta q_{\mathrm{v}}= \pm 50 \% ; \delta \tau, \delta \varepsilon_{\mathrm{a}}=0$ & $\partial Q_{\mathrm{N}} / \partial q_{\mathrm{v}}=15 \mathrm{~W} \mathrm{~m}^{-2}(\mathrm{~g} \mathrm{~kg})^{-1}$ & $+5 \mathrm{~W} \mathrm{~m}^{-2}$ \\
6. $\delta q_{\mathrm{v}}= \pm 50 \% ; \delta \tau, \delta \varepsilon_{\mathrm{a}}$ & $\partial Q_{\mathrm{N}} / \partial q_{\mathrm{v}}=25 \mathrm{~W} \mathrm{~m}^{-2}(\mathrm{~g} \mathrm{~kg})^{-1}$ & $+8 \mathrm{~W} \mathrm{~m}^{-2}$ \\
7. $\delta v= \pm 50 \%$ & $\partial Q_{\mathrm{N}} / \partial v=14 \mathrm{~W} \mathrm{~m}^{-2}(\mathrm{~m} \mathrm{~s})^{-1}$ & $+3 \mathrm{~W} \mathrm{~m}^{-2}$ \\
8. $\delta \tau= \pm 0.1$ & $\partial Q_{\mathrm{N}} / \partial \tau=-9 \mathrm{~W} \mathrm{~m}^{-2}(0.1)^{-1}$ & $-4 \mathrm{~W} \mathrm{~m}^{-2}$ \\
9. $\delta \alpha_{\mathrm{S}}= \pm 0.1$ & $\partial Q_{\mathrm{N}} / \partial \alpha_{\mathrm{S}}=-27 \mathrm{~W} \mathrm{~m}^{-2}(0.1)^{-1}$ & $-16 \mathrm{~W} \mathrm{~m}^{-2}$ \\
$10 . \delta b_{\mathrm{w}}= \pm 1 \mathrm{~m}$ w.e. & $\partial Q_{\mathrm{N}} / \partial b_{\mathrm{w}}=-12 \mathrm{~W} \mathrm{~m}^{-2}(\mathrm{~m} \mathrm{w.e.})^{-1}$ & $-3 \mathrm{~W} \mathrm{~m}^{-2}$ \\
\hline
\end{tabular}

Perturbations to the observed weather are used to repeat the sensitivity analyses of Sect. 4 , but with a realistic evolution of each summer melt season rather than the mean summer conditions. Meteorological variables are perturbed as follows: $\pm 2{ }^{\circ} \mathrm{C}$ for temperature, $\pm 50 \%$ for specific humidity and wind, \pm 0.1 for the sky clearness index (a proxy for cloud cover), and \pm 0.1 for albedo. Increments are set to give 41 realizations in each case, spanning the range of the perturbation. For example, temperature increments of $0.1^{\circ} \mathrm{C}$ are applied for the range -2 to $2^{\circ} \mathrm{C}$. Each perturbation is prescribed for all days in the original data, and the energy balance program is run for the period 2002-2012. In each experiment, all other meteorological variables are held constant except for those that are direct impacted by a perturbation (e.g., relative humidity changes with temperature).

Table 4 lists the response of mean summer (JJA) net energy, $Q_{\mathrm{N}}$, to the different meteorological perturbations. Changes in the energy fluxes can be examined in response to the perturbations, e.g., $\Delta Q_{\mathrm{N}}$ as a function of temperature anomalies, $\delta T$. We plot these values to give sensitivity curves (e.g., Figs. 5 and 6), and the slope of each curve is a measure of the sensitivity, e.g., $\mathrm{d} Q_{\mathrm{N}} / \mathrm{d} T$. Values in Table 4 are calculated through linear regression. The relationship area is generally nonlinear, so we compute the regressions for the region of the sensitivity curve within $\pm 1 \mathrm{SD}( \pm 1 \sigma)$ of the reference value for each variable. This samples a more linear range and allows a better comparison with the derivatives in Table 3. Standard deviations refer to the interannual variability, as reported in Table 1. Table 4 also lists the change in net energy associated with a $1 \sigma$ increase in each variable.

There are multiple scenarios for temperature, shown in the first four cases in Table 4. These cases represent different assumptions about the way in which atmospheric moisture and radiation fluxes respond to a temperature perturbation. The first two cases follow the assumption that relative humidity does not change. Hence, a temperature change $\delta T$ is attended by a change in specific humidity, $\delta q_{\mathrm{v}}$, to maintain constant $h$. This impacts latent heat flux and atmospheric

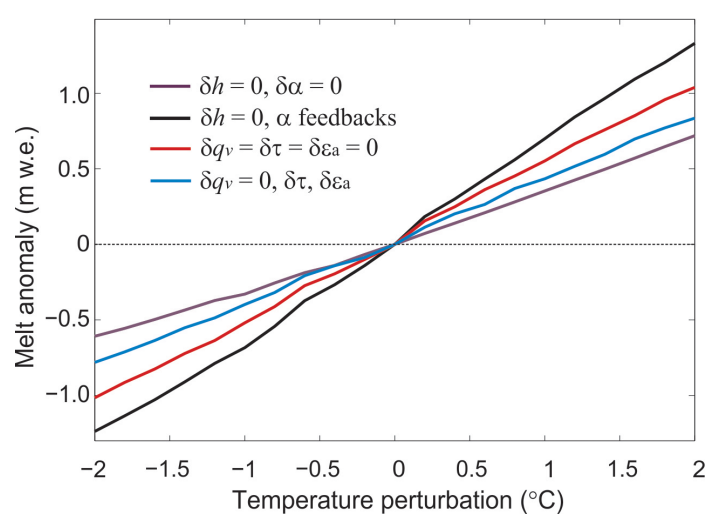

Figure 5. Sensitivity of modelled summer (JJA) melt to temperature perturbations for different assumptions, as per Table 4. The reference (mean 2002-2012) JJA melt is $2.32 \mathrm{~m}$ w.e.

emissivity. Cases 1 and 2 show the net energy sensitivity to this scenario without and with albedo feedbacks. The next two cases include albedo feedbacks but assume no change in specific humidity, $\delta q_{\mathrm{v}}=0$; hence relative humidity must respond. Cases 3 and 4 are without and with atmospheric radiation feedbacks to the changed relative humidity.

Summer melt sensitivity for the four different temperature perturbation scenarios is plotted in Fig. 5. Case 1 lacks albedo feedbacks and corresponds to a net energy sensitivity of $13 \mathrm{~W} \mathrm{~m}^{-2}{ }^{\circ} \mathrm{C}^{-1}$, which is comparable to the theoretical temperature sensitivities in Table 3 . This is due to direct temperature/humidity impacts on incoming radiation fluxes, sensible heat flux, and latent heat flux. Cases 2-4 include albedo feedbacks. This can be considered to be more realistic, and the albedo feedbacks have a roughly 2-fold amplification effect on the temperature perturbation. Under constant $h, \mathrm{~d} Q_{\mathrm{N}} / \mathrm{d} T=27 \mathrm{~W} \mathrm{~m}^{-2}{ }^{\circ} \mathrm{C}^{-1}$ (cf. Fig. 6a), representing a $28 \%$ increase in summer melt for a $1{ }^{\circ} \mathrm{C}$ warming. This decreases by $6-10 \mathrm{~W} \mathrm{~m}^{-2}{ }^{\circ} \mathrm{C}^{-1}$ in cases 3 and 4 , where $q_{\mathrm{v}}$ is held constant. Some of the reduced energy comes from the elimination of latent energy feedbacks. Case 4, with at- 

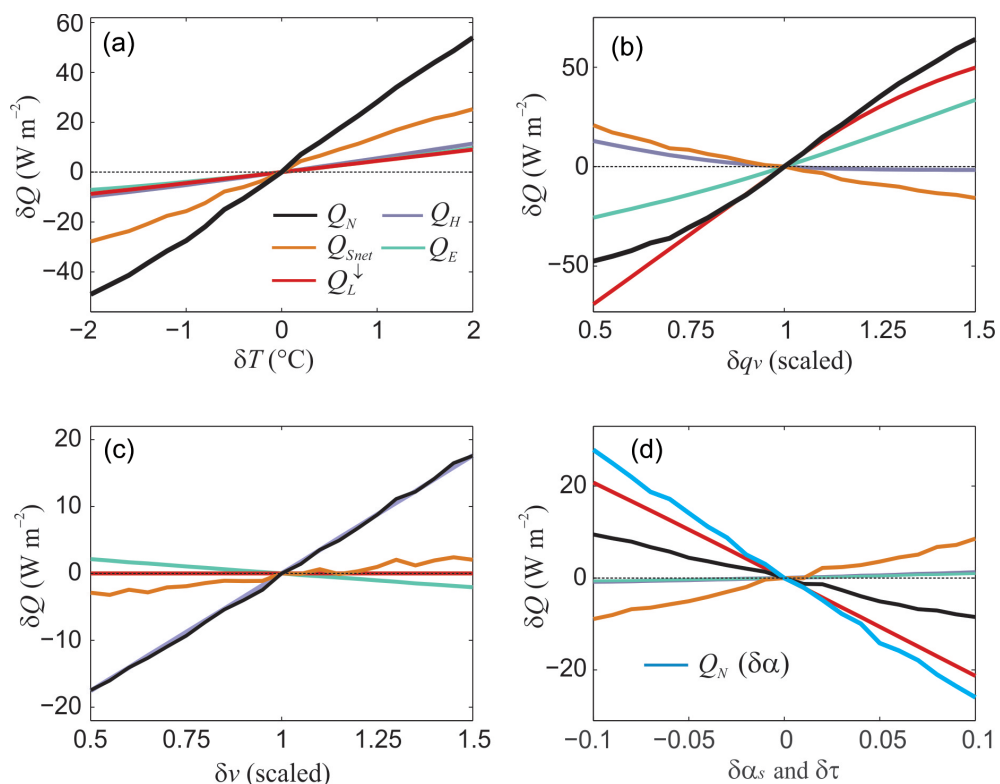

Figure 6. Sensitivity of the surface energy fluxes at Haig Glacier to changes in (a) temperature (case 2), (b) specific humidity (case 6), (c) wind speed (case 7), and (d) atmospheric transmittance (case 8) and albedo (blue line, case 9). All lines are anomalies relative to the baseline data from the period 2002-2012, and they indicate the mean sensitivity of the different energy fluxes over this period. Please note the different $y(\delta Q)$ scales.

mospheric radiation feedbacks, reduces energy further as decreased cloud cover (via higher $\tau$ ) reduces incoming longwave radiation more strongly than it increases shortwave fluxes in the model. Here, too, the numerical model gives a similar result to the theoretical prediction.

Figure 6a plots the response of the different surface energy fluxes for the reference model, case 2. Net shortwave radiation dominates the temperature response, over $Q_{\mathrm{H}}, Q_{\mathrm{E}}$, and $Q_{\mathrm{L}}^{\downarrow}$. Figure $6 \mathrm{~b}-\mathrm{d}$ provide similar details for perturbations in humidity, wind, clearness index, and albedo (cases 5-9 in Table 4). Sensitivity to humidity changes is relatively strong, through the combined impacts of latent and longwave fluxes (Fig. 6b). Case 6 is shown in this figure, including feedbacks on the atmospheric radiation. Incoming longwave radiation is strongly augmented by the increases in absolute and relative humidity and accounts for about $70 \%$ of the net energy sensitivity to specific humidity. It is partially offset by cloud feedbacks, however, which reduce incoming shortwave radiation.

For increases in both temperature and humidity, the mean summer latent heat flux switches sign from negative (Table 2) to positive; that is, latent heat flux becomes a source rather than sink of energy under warmer and wetter conditions. In contrast, latent heat flux remains negative, but small, under increases in wind speed (Fig. 6c). Energy balance sensitivity to wind perturbations is primarily associated with the sensible heat flux.

Net energy perturbations due to albedo and clearness index in Fig. 6d are independent of each other, but they are plotted together for convenience. Albedo sensitivity over the range \pm 0.1 is relatively high, with a decrease in net energy of $27 \mathrm{~W} \mathrm{~m}^{-2}(28 \%)$ for an increase in albedo of 0.1. Changes in sky clearness index (atmospheric transmissivity) have a lower impact due to the compensating influences on incoming shortwave and longwave radiation. Reduced cloud cover (higher $\tau$ ) gives an overall reduction in net energy at our site, as longwave radiation effects are dominant.

\section{Sensitivity to winter snow accumulation}

Changes in the winter mass balance also influence the summer melt season. Interannual variability in the amount of snow is implicit in the simulations, as the spring (1 May) snowpack depth is initialized with the measured winter mass balance for each year, $b_{\mathrm{w}}$ (Marshall, 2014). However, these experiments do not control for the influence of snow depth on summer melt extent.

To examine this, we force the energy balance model over a range of winter mass balance conditions, $b_{\mathrm{w}} \in[0.36,2.36] \mathrm{mw}$.e. This is $\pm 1 \mathrm{~m}$ w.e. relative to the mean observed value at the AWS site, $1.36 \pm 0.27 \mathrm{~m}$ w.e. The melt model is run through 11 years of weather, 20022012 , with the different values of winter mass balance as an initial condition. Figure 7 plots the average evolution of seasonal snowpack depth and albedo from May through September for this suite of experiments. Transitions from seasonal snow to ice span from early July to mid-September. Albedo spikes in Fig. $7 \mathrm{~b}$ are due to summer snow events, 
which become more frequent as temperatures cool in September.

The net energy balance perturbations that accompany these scenarios are shown for two choices of the minimum snow albedo (Fig. 7c). Observations of late-summer snow at the site are in the range $0.3-0.4$, the two values presented here. The plot is asymmetric: net energy is more sensitive to reduced winter snow depths, which result in an earlier transition to exposed glacier ice. A $20 \%(1 \sigma)$ reduction in $b_{\mathrm{w}}$ gives a net energy increase of about $4 \mathrm{~W} \mathrm{~m}^{-2}(4 \%)$, and the sensitivity increases nonlinearly with increasingly lower snow depths. The influence from a deep winter snowpack is comparatively muted: $1-2 \mathrm{~W} \mathrm{~m}^{-2}$ reductions in $Q_{\mathrm{N}}$ for a $20 \%$ increase in the winter snow thickness. Perturbations in $Q_{\mathrm{N}}$ asymptote once seasonal snow is deep enough to survive through the summer.

The influence of the winter snowpack at this site is similar in magnitude to the net energy impacts of interannual variations in wind speed but less important to the summer melt than observed variations in temperature, albedo, or cloud cover. This result is partly due to the relatively low contrast between late-summer snow albedo and bare-ice albedo at this site. If late-summer snow has a higher albedo, a deep winter snowpack is more effective at reducing the net energy and summer melt. The shape of the sensitivity curve would change for locations with higher-albedo snow as well as for sites in the lower ablation zone, where ice is exposed early in the melt season. A heavy winter snowpack would have a comparatively stronger role in this case. The result in Fig. 7 is therefore more site specific than for the other meteorological perturbations.

\section{NARR-based surface energy balance reconstructions, 1979-2014}

To examine energy balance sensitivity over a longer time period and with joint variation in meteorological variables, we run the energy balance model forced by NARR atmospheric reconstructions from 1979 to 2014 (Mesinger et al., 2006). This provides a more complete picture of interannual variability, while comparison of NARR predictions with measurements over the period 2002-2012 also allows us to assess the skill with which fluctuations in surface energy balance and summer melt can be captured in an atmospheric model that does not explicitly resolve the alpine and glacier conditions.

We use a perturbation approach as in Sect. 5, taking NARR daily meteorological fields as anomalies relative to the mean NARR conditions for the period 2002-2012. Anomalies in near-surface temperature, specific humidity, wind speed, pressure, incoming shortwave radiation, and incoming longwave radiation are used to drive the model for the 36-year period 1979-2014. Perturbations are introduced as anomalies relative to the mean observed conditions. NARR input fields allow us to introduce multiple perturbations at once, with magnitudes that are physically meaningful and meteorologically consistent covariance of variables.

NARR has an effective spatial resolution of $32 \mathrm{~km}$, and we extract mean daily data from the grid cell over Haig Glacier. This grid cell has an elevation of $2214 \mathrm{~m}$, about $450 \mathrm{~m}$ lower than the AWS site. By using daily weather anomalies, we avoid most biases associated with the different altitude of the NARR grid cell. However, variations in some fields such as specific humidity, pressure, and temperature can be larger at lower elevations and over non-glacierized land surface types. Since we use meteorological fluctuations as perturbations, this is potentially problematic. Inspection of the summer variance in the different meteorological inputs over the reference period 2002-2012 indicates that this does not appear to be an issue. Standard deviations of each variable, calculated from mean JJA values, are as follows: temperature, $0.8^{\circ} \mathrm{C}$; specific humidity, $0.2 \mathrm{~g} \mathrm{~kg}^{-1}$; wind speed, $0.3 \mathrm{~m} \mathrm{~s}^{-1}$; incoming shortwave radiation, $6 \mathrm{~W} \mathrm{~m}^{-2}$; and incoming longwave radiation, $3 \mathrm{~W} \mathrm{~m}^{-2}$. Temperature, humidity, and wind values are equivalent to the observed range of variability from 2002 to 2012 (Table 1), but the radiation fluxes are less variable. The effects of a lower elevation in the NARR grid cell appear to be less than those associated with systematic biases in the reanalysis, e.g., not enough variability in cloud conditions.

The energy balance model requires an estimate of winter snow accumulation. We base this on cumulative NARR precipitation for the period September to May of each year, normalized to the observed value of $1.36 \mathrm{~m}$ w.e. at the Haig Glacier AWS site. This permits interannual variability in the winter snowpack thickness to be included in the simulations by scaling the mean observed value up or down based on the NARR winter precipitation totals. We use this as an initial condition for the melt model (i.e., for 1 May snow depth).

We examine the sensitivity of net summer energy balance and melt to interannual variations in each weather variable in the NARR forcing. Table 5 reports the NARR-based surface energy fluxes and melt for JJA and MJJAS, averaged over the period 1979-2014. Mean values are all within $2 \mathrm{~W} \mathrm{~m}^{-2}$ of the reference surface energy fluxes (Table 2), derived from the in situ data, but there are some significant differences in the standard deviation, which is a measure of the interannual variability. As noted above, incoming shortwave radiation has about half of the variability in the 36-year NARR record as observed in the 11-year measurement period, and variance in incoming longwave radiation is also less than observed. This implies more uniform summer cloud conditions in the reanalysis compared to the observational period.

Average summer albedo is also less variable in the model than the observations, and the mean value in the NARR-forced model is too low for May through September ( 0.55 vs. an observed value of 0.60 ). Most of this difference is associated with a low value of September albedo in the model; we are generally underestimating September snow events and predicting too late a transition from the end-of- 

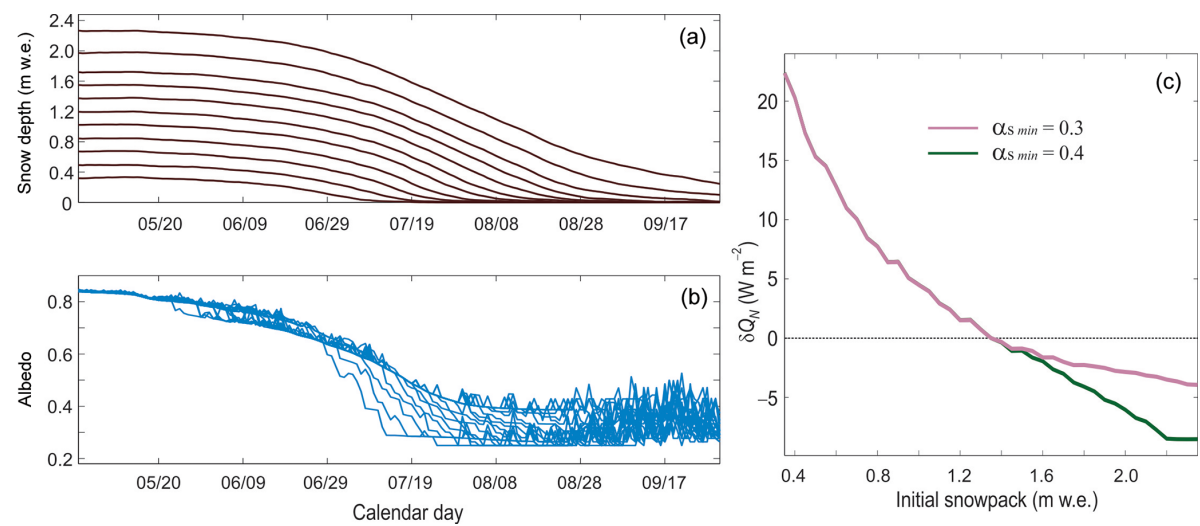

Figure 7. Sensitivity to the winter mass balance, examined by varying 1 May snow depth from 0.36 to $2.36 \mathrm{~m}$ w.e., relative to the reference value of $1.36 \mathrm{~m}$ w.e. at the glacier AWS. (a) Snow depth and (b) albedo through the summer melt season, 1 May-30 September, for the different initial snow depths. (c) Net summer (JJA) energy balance change as a function of the winter mass balance for two different settings of the minimum snow albedo.

Table 5. Summer surface energy balance fluxes on Haig Glacier as forced by the North American Regional Reanalysis (NARR) daily weather fields, 1979-2014. NARR inputs are taken as perturbations to the mean observed values. Melt is in $\mathrm{m}$ w.e., and all fluxes have unit $\mathrm{W} \mathrm{m}^{-2}$.

\begin{tabular}{lccccccccc}
\hline Period & $Q_{\mathrm{S}}^{\downarrow}$ & $\alpha_{\mathrm{S}}$ & $Q_{\mathrm{L}}^{\downarrow}$ & $Q_{\mathrm{L}}^{\uparrow}$ & $Q_{\mathrm{H}}$ & $Q_{\mathrm{E}}$ & $Q_{\mathrm{C}}$ & $Q_{\mathrm{N}}$ & Melt \\
\hline JJA & $227 \pm 7$ & $0.53 \pm 0.05$ & $275 \pm 4$ & $311 \pm 1$ & $27 \pm 4$ & $-3 \pm 3$ & $2 \pm 1$ & $95 \pm 14$ & $2.28 \pm 0.42$ \\
MJJAS & $215 \pm 6$ & $0.55 \pm 0.04$ & $271 \pm 4$ & $308 \pm 2$ & $22 \pm 3$ & $-5 \pm 3$ & $3 \pm 1$ & $73 \pm 10$ & $2.68 \pm 0.50$ \\
\hline
\end{tabular}

summer to the winter accumulation season. This transition occurs sometime in September or October each year in our study period. September is mixed on the glacier, with fresh snowfall alternating with periods of melting. This raises the average albedo on the glacier, but our albedo parameterization does not fully capture this.

Figure 8 a plots time series of the NARR-forced surface energy balance terms, and Fig. 8b-d show the relations between net energy and selected meteorological variables. These provide a visual indication of the strength of each variable as a predictor of summer melt. Regressions through these data points give estimates of net energy sensitivity, e.g., $\partial Q_{\mathrm{N}} / \partial T$, as seen in actual realizations of the summer weather conditions. These gradients can be thought of as the melt sensitivity to interannual variability or trends in each weather variable.

The resulting sensitivities are given in Table 6 , as well as linear correlation coefficients between $Q_{\mathrm{N}}$ and all glaciometeorological variables that are used in the energy balance model. These simulations are forced with NARR radiation flux anomalies, so we do not parameterize the incoming longwave or shortwave radiation in these tests. The clearness index, $\tau$, is not used, but it can be calculated from the NARR relative humidity estimate, via Eq. (10), or more directly through the fraction of incoming shortwave radiation relative to the clear-sky potential radiation. We test both approaches and find similar results. Values for $\partial Q_{\mathrm{N}} / \partial \tau$ reported in Table 6 are averaged from the two approaches. We also report the direct relation between NARR total cloud cover and net energy; cloud cover is available in the reanalysis, but we do not have in situ data to compare with

Temperature and albedo have the strongest influences on summer energy balance and melt. Fluctuations in specific humidity and incoming longwave radiation also correlate strongly with interannual variability in the summer energy budget. Wind speed, cloud conditions, and incoming shortwave radiation do not strongly contribute to the year-to-year variations in summer melt over the NARR period. There is a weak, positive relationship between the clearness index and net radiation in the NARR-forced results, indicating that increased shortwave radiation associated with reduced cloud cover has a stronger role than the associated reduction in longwave radiation.

These sensitivities can be compared with those in Sect. 5 (Table 4), but they differ in that the NARR forcing has multiple joint perturbations. This is realistic as the meteorological variables covary systematically, but it means that it is not possible to isolate the role of a single variable, such as temperature. A temperature change impacts several of the energy fluxes, but coincident changes in, e.g., humidity and radiation fluxes may reinforce or reduce the temperature impacts. Results in Table 6 should therefore be interpreted as the "net" or "effective" influence of each weather variable on the summer energy balance, and some of them may have correlations that are more coincidental than casual. Most results are nonetheless similar in magnitude to the theoretical and modelling 
Table 6. Correlation and sensitivity of different weather variables to the mean summer (JJA) net energy flux, $Q_{\mathrm{N}}$, for the NARR simulations, 1979-2014. "Cloud" is the NARR total cloud fraction.

\begin{tabular}{lrlr}
\hline Variable & Correlation & Sensitivity & $\delta Q_{\mathrm{N}}$ for $+1 \sigma$ \\
\hline$T\left({ }^{\circ} \mathrm{C}\right)$ & 0.84 & $\partial Q_{\mathrm{N}} / \partial T=14 \mathrm{~W} \mathrm{~m}^{-2}\left({ }^{\circ} \mathrm{C}\right)^{-1}$ & $+10 \mathrm{~W} \mathrm{~m}^{-2}$ \\
$q_{\mathrm{v}}\left(\mathrm{g} \mathrm{kg}^{-1}\right)$ & 0.50 & $\partial Q_{\mathrm{N}} / \partial q_{\mathrm{v}}=25 \mathrm{~W} \mathrm{~m}^{-2}(\mathrm{~g} \mathrm{~kg})^{-1}$ & $+7 \mathrm{~W} \mathrm{~m}^{-2}$ \\
$v\left(\mathrm{~m} \mathrm{~s}^{-1}\right)$ & 0.00 & $\partial Q_{\mathrm{N}} / \partial v=-4 \mathrm{~W} \mathrm{~m}^{-2}\left(\mathrm{~m} \mathrm{~s}^{-1}\right.$ & $-1 \mathrm{~W} \mathrm{~m}^{-2}$ \\
$Q_{\mathrm{S}}^{\downarrow}\left(\mathrm{W} \mathrm{m}^{-2}\right)$ & 0.14 & $\partial Q_{\mathrm{N}} / \partial Q_{\mathrm{S}}^{\downarrow}=0.3 \mathrm{~W} \mathrm{~m}^{-2}\left(\mathrm{~W} \mathrm{~m}^{-2}\right)^{-1}$ & $+2 \mathrm{~W} \mathrm{~m}^{-2}$ \\
$Q_{\mathrm{L}}^{\downarrow}\left(\mathrm{W} \mathrm{m}^{-2}\right)$ & 0.64 & $\partial Q_{\mathrm{N}} / \partial Q_{\mathrm{L}}=2 \mathrm{~W} \mathrm{~m}^{-2}\left(\mathrm{~W} \mathrm{~m}^{-2}\right)^{-1}$ & $+8 \mathrm{~W} \mathrm{~m}^{-2}$ \\
$\tau$ & 0.25 & $\partial Q_{\mathrm{N}} / \partial \tau=15 \mathrm{~W} \mathrm{~m}^{-2}(0.1)^{-1}$ & $+4 \mathrm{~W} \mathrm{~m}^{-2}$ \\
Cloud & -0.19 & $\partial Q_{\mathrm{N}} / \partial c=-8.1 \mathrm{~W} \mathrm{~m}^{-2}(0.1)^{-1}$ & $-3 \mathrm{~W} \mathrm{~m}^{-2}$ \\
$\alpha_{\mathrm{S}}$ & -0.83 & $\partial Q_{\mathrm{N}} / \partial \alpha_{\mathrm{S}}=-26 \mathrm{~W} \mathrm{~m}^{-2}(0.1)^{-1}$ & $-11 \mathrm{~W} \mathrm{~m}^{-2}$ \\
$b_{\mathrm{w}}(\mathrm{m}$ w.e. $)$ & -0.15 & $\partial Q_{\mathrm{N}} / \partial b_{\mathrm{w}}=-3 \mathrm{~W} \mathrm{~m}^{-2}(\mathrm{~m} \mathrm{w.e.})^{-1}$ & $-1 \mathrm{~W} \mathrm{~m}^{-2}$ \\
\hline
\end{tabular}
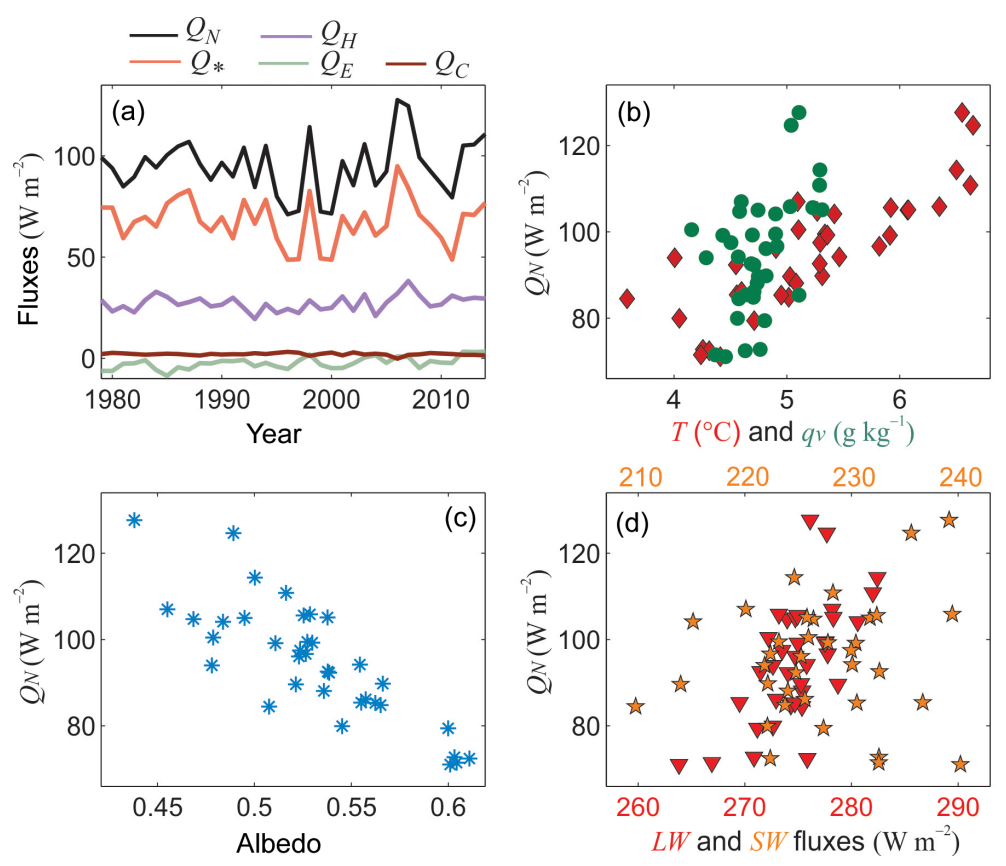

Figure 8. (a Mean summer (JJA) NARR-forced surface energy fluxes at Haig Glacier, 1979-2014. Mean summer net energy as a function of (b) temperature and specific humidity, (c) albedo, and (d) incoming shortwave and longwave radiation. Table 6 gives the associated correlations.

results (Tables 3 and 4), which are based on the in situ data. The largest exception is the relation between clearness index (cloud cover) and net energy, which is opposite in sign.

\section{Discussion}

We have taken three different approaches to estimate summer (JJA) energy balance and melt sensitivity at Haig Glacier: (i) theoretical, perturbing one variable at a time; (ii) a numerical model, restricting model experiments to single perturbations but allowing for internal feedbacks to be modelled; and (iii) through perturbations from a regional climate reanalysis, allowing multiple variables to change at once. Here we briefly summarize and interpret the integrated results from these different methods.

\subsection{Haig Glacier energy balance sensitivities and feedbacks}

Interannual variations in temperature and albedo have the strongest influence on summer energy balance in all three approaches to assessing Haig Glacier melt sensitivity (Fig. 9). Fluctuations in humidity and longwave radiation are also important, while variations in cloud cover $(\tau)$, wind speed, and the winter snowpack thickness are less influential on the summer energy budget and melt extent at this site. 


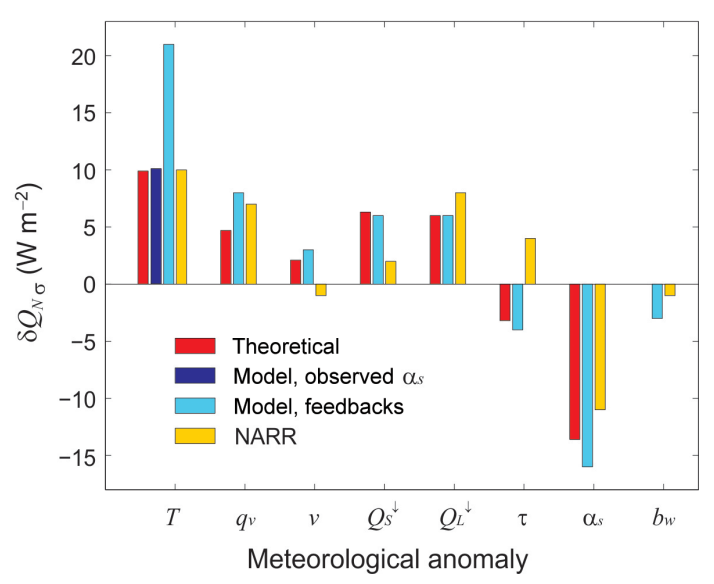

Figure 9. Net energy sensitivity to a $1 \sigma$ perturbation in different meteorological variables: comparison of theoretical, in situ numerical model, and NARR-based estimates.

Temperature changes are generally thought of as the main driver of glacier advance and retreat, through combined influences on the surface energy budget, snow accumulation, and summer melt season. Sensitivities to temperature are commonly expressed as the change in summer or net mass balance per unit warming. Sample mass balance sensitivities reported in the literature are $-0.6 \mathrm{~m}$ w.e. ${ }^{\circ} \mathrm{C}^{-1}$ on Morteratschgletscher, Switzerland (Klok and Oerlemans, 2004), and Illecillewaet Glacier, British Columbia (Hirose and Marshall, 2013), $-0.68 \pm 0.05 \mathrm{~m}$ w.e. ${ }^{\circ} \mathrm{C}^{-1}$ for a suite of glaciers in Switzerland (Huss and Fischer, 2016), and $-0.86 \mathrm{~m}$ w.e. ${ }^{\circ} \mathrm{C}^{-1}$ on South Cascade Glacier, Washington (Anslow et al., 2008). Values as high as $-2.0 \mathrm{~m}$ w.e. ${ }^{\circ} \mathrm{C}^{-1}$ are reported for Brewster Glacier, New Zealand (Anderson et al., 2010).

These values are for the annual mass balance, but they are dominated by the summer melt response to warming. They represent a melt sensitivity of about $30 \%{ }^{\circ} \mathrm{C}^{-1}$ for the examples in the Alps and western North America. When we introduce temperature perturbations in the absence of albedo feedbacks, we find a relatively muted energy balance response, about $13 \%{ }^{\circ} \mathrm{C}^{-1}$. The increase in net energy is distributed about equally across the sensible heat flux, incoming longwave radiation, and latent heat flux, and we have similar results for both the theoretical and numerically modelled temperature perturbations. Albedo feedbacks increase the net energy sensitivity to $28 \%{ }^{\circ} \mathrm{C}^{-1}$ or $-0.66 \mathrm{~m}$ w.e. ${ }^{\circ} \mathrm{C}^{-1}$, in accord with previous studies. The exact number depends on assumptions about humidity; if specific humidity increases with temperature (e.g., by holding relative humidity constant), temperature sensitivity is higher.

The albedo feedback results from two main ways that temperature influences the seasonal albedo evolution. A more intense melt season gives rise to a lower snow albedo and an earlier transition from seasonal snow cover to glacial ice. We do not explicitly model impurities or snow albedo processes (e.g., grain metamorphosis, effects of snow-water content on the albedo), but we parameterize the seasonal albedo evolution as a function of cumulative PDD (Eq. 20), which makes the model directly sensitive to temperature perturbations.

Temperature changes have several additional, indirect impacts, including (i) a longer melt season, (ii) a greater fraction of time with surface temperatures at the melting point during the year, i.e., with reduced overnight cooling and refreezing, and (iii) an increase in the frequency of summer rain vs. snow events. Summer snow events have an important impact on surface albedo, with fresh snow strongly attenuating melt. Each of these processes contributes to the strong impact of temperature anomalies on glacier melt. Combined with the albedo feedbacks, these processes and help to explain why glaciers are strongly sensitive to temperature change.

Direct changes to albedo have an influence on summer energy balance and melt extent that is comparable to the temperature influence, $\sim 17 \%$ for a change in albedo equal to the interannual albedo fluctuations, 0.06. Mean summer albedo differences arise as a feedback to other meteorological forcings that drive the summer snow melt, but interannual albedo variations also occur more directly, as a consequence of summer snowfall events, as a function of winter accumulation totals, or due to impurity loading (e.g., black carbon deposition). The latter has been observed in association with forest fires in British Columbia. Strong fire seasons occurred twice during our period of study, in 2003 and 2015, and each left a measurably darker glacier surface. For instance, the average albedo recorded at the AWS site in August 2003 was 0.13 .

We found a relatively weak influence of winter mass balance on the summer melt extent. A low snowpack depth has a greater impact, through an earlier transition to low-albedo bare ice. A deep winter snowpack has the opposite influence, supporting a higher average summer albedo, but the influence is weaker because the AWS site is in the upper ablation area, where the seasonal snowpack persists until late summer in most years. The effects of greater winter accumulation plateau once there is enough snow to survive the summer; beyond this point, additional snow has no effect on the summer albedo or melt extent. Sensitivity to winter mass balance would likely be stronger at lower altitudes on the glacier and for the overall glacier mass balance.

Humidity changes can also be considered a feedback to temperature, but this is not certain; specific humidity varies as a function of local- to synoptic-scale moisture sources and weather patterns, and these are not necessarily coupled to temperature conditions. For instance, warm conditions at Haig Glacier often accompany anticyclonic ridging in the summer months, during which time southerly flows and upper-level subsidence promote dry, clear-sky conditions (low $q_{\mathrm{v}}$ and $h$ ). At other times, westerly flows bring warm, moist Pacific air masses and humidity, temperature, and cloud cover covary. Interannual variability in specific humidity has a significant impact on summer energy and melt extent, an $\sim 8 \%$ change for a perturbation of $0.3 \mathrm{~g} \mathrm{~kg}^{-1}(1 \sigma)$. 
This effects net energy through impacts on the latent heat flux and incoming longwave radiation. The latter is partially compensated by accompanying changes in incoming shortwave radiation.

With all three methods, cloud cover shows up as a relatively weak influence on summer net energy at this site, $\sim 4 \%$ for a $1 \sigma$ variation in the clearness index (Fig. 9). This result is a consequence of the offsetting effects of cloud cover on the shortwave and longwave fluxes. The sign of the relationship is also uncertain. In isolation, interannual fluctuations in shortwave and longwave radiation have a moderate influence on the summer net energy (Fig. 9), so these are important; they are just not simply related to the cloud cover index, $\tau$.

\subsection{NARR results}

NARR results are broadly consistent with the in situ-based and theoretical sensitivities, in terms of the relative importance of different meteorological parameters to interannual variability in summer energy balance and melt. The influence of interannual temperature fluctuations appear to be weaker than the other sensitivity experiments would suggest, $\sim 15 \%{ }^{\circ} \mathrm{C}^{-1}$. All feedbacks discussed above are active in the NARR-based simulations. The impacts of temperature variability on net energy and melt could be partially compensated by other systematic changes in the energy budget. For instance, warm temperatures are often associated with calm, clear-sky conditions that reduce the incoming longwave radiation and the turbulent fluxes.

Temperature nonetheless emerges as the most important variable explaining interannual variations in net energy. Mean summer net energy and temperature are highly correlated $(r=0.84)$. This reinforces the argument that temperature indices offer a good proxy for net energy and summer melt extent (e.g., Ohmura, 1987).

There are two other discrepancies in the NARR-forced results. Year-to-year variance in incoming radiation fluxes is less than observed, pointing to poor representation of interannual cloud variability in the reanalysis. The variability is still positively correlated with the in situ data (e.g., $r=0.50$ for the correlation between incoming JJA shortwave radiation in NARR and in the data from 2002 to 2012). Hence, NARR is picking up some of the observed variability, but it is muted. The sensitivities to the radiation fluxes may still be representative, as there is still some interannual variability for which one can assess the relation between $Q_{\mathrm{N}}$ and the radiation fluxes. However, the poor representation of the radiation fluxes and cloud conditions can be expected to reduce the skill of NARR-forced mass and energy balance reconstructions; this requires further study.

The other main difference with the NARR forcing is a switch in sign in the sensitivity to changes in cloud cover, as analyzed through either $\tau$ or the NARR-predicted total cloud cover. Clear-sky conditions have a positive relation with $Q_{\mathrm{N}}$ in the NARR-driven simulations, signalling that incoming shortwave radiation fluxes exert more influence than incoming longwave fluxes for net summer energy. Clear-sky conditions (less cloud cover) give increased shortwave radiation and a lesser decrease in longwave radiation, resulting in increased net energy. The theoretical and in situ sensitivities predict the opposite result: reduced net energy with clearer skies. The relationship is relatively weak, so it is possible that there are confounding variables in the NARR simulations once again, such as temperature effects masking the cloud relationship.

We do not test the ability and skill of NARR-forced energy and mass balance reconstructions here. This requires further study. In general, the perturbation method eliminates biases in the mean NARR variables, but a realistic representation of the variability and long-term trends in reanalysis fields is important to realistic representations of the glacier mass balance record and meltwater runoff. It would be instructive to analyze the synoptic weather patterns and weather anomalies in high-melt vs. low-melt summers in the NARR-driven simulations. We recommend an investigation of specific weather systems and their associated meteorological and energy balance conditions in followup work.

\subsection{Representativeness of the results}

We have designed the sensitivity approach and the model to be applicable in regional studies, e.g., in a distributed model of glacier energy balance, forced by climate model reanalyses or projections. However, we did not expand our scope to other sites within the present study. In principle, the theoretical sensitivities (i.e., from the same set of equations) could be calculated for different baseline meteorological conditions, such as maritime or tropical environments. The method, rather than the specific Haig Glacier results, could be exported to other glacierized environments.

At regional scales, Haig Glacier energy balance sensitivities might be more transferrable, since similar summer climate conditions prevail across the Canadian Rocky Mountains (Ebrahimi and Marshall, 2015). Regional, multiyear reconstructions of glacier meltwater runoff might be feasible through a perturbation approach to summer mass balance, driven by meteorological anomalies from station data or climate models. This needs to be tested, however, for sensitive parameterizations such as the albedo model. It is uncertain whether the Haig Glacier bare-ice and old-snow albedo are regionally representative.

Within Haig Glacier itself, our AWS site is in the upper ablation area, near the equilibrium line altitude (ELA). Results are specific to the snow and ice albedo, snowpack depth, and meteorological/energy balance conditions at this location. We have not examined the representativeness of the results to other parts of the glacier, but summer melt extent and mass balance at the AWS site are strongly correlated with glacier-wide mass balance. We recommend additional work 
to calculate an average set of glacier sensitivities and assess whether the values presented here are representative. We suspect that sensitivity of net energy to winter snow depth and the strength of albedo feedbacks will vary across the glacier.

\subsection{Recommended model improvements}

Model improvements are recommended with respect to our treatment of the glacier surface albedo and precipitation modelling. The energy balance, albedo, and melt models perform well in the core summer melt season, June through August, when summer snowfall is infrequent and impacts on the albedo are transient. We systematically underestimate September albedo, however; better treatments of latesummer snow accumulation and the transition to the winter accumulation season are needed.

Our meltwater drainage model is also simplistic. We assume that water drains efficiently from the glacier surface, but in fact water has been observed to pond and refreeze on the surface. Re-melting of this superimposed ice consumes energy and reduces the total summer runoff.

A more realistic treatment of year-round snow accumulation is also needed in order to carry out model-based glacier mass balance reconstructions. We rely on observed winter mass balance for the studies here, but historical reconstructions and future projections require a way to reliably estimate snow accumulation from climate models. NARR precipitation in the Haig Glacier grid cell poorly represents the observed winter accumulation totals.

We have done tests to verify that the daily, parameterized model performs well relative to direct forcing with $30 \mathrm{~min}$ AWS data, but some simplifications embedded in the daily model need to be examined. For instance, we assume constant cloud cover/clearness index over the day; systematic diurnal variations in cloud cover would affect the net radiation in ways that we do not capture. Overnight clouds serve to increase energy flux to the glacier, while daytime clouds reduce the incoming radiation. Effects like these become complicated to model or parameterize, but could bias our sensitivity results to cloud cover.

\section{Conclusions}

Sensitivity studies presented here extend the foundational work of Oerlemans and Fortuin (1992) and others, which has generally been done on glacier mass balance sensitivity to changes in temperature and precipitation. Our study is limited to summer mass balance at one location, but our results offer insight into the influence of different meteorological variables and energy fluxes, their year-to-year variability, and the role of isolated vs. collective forcings, feedbacks, and interactions on summer melt extent.

There is a good correspondence between the theoretical sensitivities and those derived from the numerical energy bal- ance model, when feedbacks are omitted. This supports the potential application of the theoretical sensitivities to explore energy balance sensitivities under different climate regimes. This method can be transferred directly to other sites.

Temperature and albedo variations exert the strongest controls on year-to-year variability in summer melt at our site. While albedo can fluctuate independent of temperature, e.g., through the influence of the winter snowpack depth or aerosol loading, it is also a powerful feedback mechanism to temperature and melt season evolution. In our model, albedo feedbacks give a 2 -fold increase in the net energy balance sensitivity to a temperature perturbation, amplifying the summer melt response from 13 to $\sim 28 \%{ }^{\circ} \mathrm{C}^{-1}$. Temperature and albedo fluctuations are also the strongest influences on interannual melt variations in the NARR-forced surface energy balance, but the melt sensitivity to temperature variations is about $15 \%{ }^{\circ} \mathrm{C}^{-1}$, weaker than our result from the control experiments. This may be because the covariation of other variables in the surface energy balance partially offsets the temperature forcing.

Humidity fluctuations are also effective in influencing the net energy, through their impacts on latent heat flux and incoming radiation fluxes. Wind speed, cloud conditions, and the winter snowpack thickness are less important to the summer energy balance and melt extent at our site. The relationship with cloud conditions is statistically weak and we do not have confidence in the sign; we recommend further work to assess the influence of cloud cover on summer net radiation at this site and elsewhere.

Our results suggest that it may be reasonable to model glacier melt sensitivity at this site to temperature forcing, while ignoring variability and change in other weather conditions such as wind speed and cloud cover. This is the implicit premise in temperature-index melt models, and they can be tuned to work well at our site. We hesitate to recommend this though. Albedo feedbacks are crucial to include in assessments of glacier response to temperature change, and are not physically represented in most temperature-index models. Variations in humidity and their influence on melt are not negligible, and all terms in the surface energy budget contribute to the daily and interannual fluctuations in net energy.

Our modelling approach for surface energy balance is well-suited to a distributed energy balance model, applying the perturbation approach to larger scales (e.g., mountain ranges). Climate models simulate all of the relevant meteorological fields, and both past reanalyses and future projections can be driven using the perturbation approach introduced here. Meteorological sensitivities under different climate regimes (e.g., maritime, polar, or tropical conditions) can also be explored using this framework to help understand regional differences in glacier sensitivity to climate variability and change. 


\section{Data availability}

The data and the MATLAB code used in this study are available on request from the authors_ (samaneh.ebrahimi@ucalgary.ca or shawn.marshall@ucalgary.ca).

Acknowledgements. This contribution benefitted from the detailed reviews and insights of two anonymous reviewers and the Editor. It is much improved thanks to the reviewers' suggestions. We thank the Natural Sciences and Engineering Research Council (NSERC) of Canada for long-term support of the Haig Glacier study. Samaneh Ebrahimi is financially supported through NSERC and the Alberta Water Research Institute project Predicting Alberta's Water Future. We are indebted to numerous graduate students and research assistants who helped to collect data and maintain instrumentation at Haig Glacier since 2001.

Edited by: M. van den Broeke

Reviewed by: R. H. Giesen and one anonymous referee

\section{References}

Anderson, B., Mackintosh, A., Stumm, D., George, L., Kerr, T., Winter-Billington, A., and Fitzsimons, S.: Climate sensitivity of a high-precipitation glacier in New Zealand, J. Glaciol., 56, 114$128,2010$.

Andreas, E. L.: Parameterizing scalar transfer over snow and ice: a review, J. Hydrometeorol., 3, 417-432, 2002.

Anslow, F. S., Hostetler, S., Bidlake, W. R., and Clark, P. U.: Distributed energy balance modeling of South Cascade Glacier, Washington and assessment of model uncertainty, J. Geophys. Res.-Ea. Surf., 113, 1-18, doi:10.1029/2007JF000850, 2008.

Arendt, A., Walsh, J., and Harrison, W.: Changes of glaciers and climate in northwestern North America during the late twentieth century, J. Climate, 22, 4117-4134, 2009.

Braithwaite, R. J. and Raper, S. C.: Glaciers and their contribution to sea level change, Phys. Chem. Earth A/B/C, 27, 1445-1454, 2002.

Brock, B. W., Willis, I. C., and Sharp, M. J.: Measurement and parameterisation of albedo variations at Haut Glacier d'Arolla, Switzerland, J. Glaciol., 46, 675-688, 2000.

Brutsaert, W.: On a derivable formula for long-wave radiation from clear skies, Water Resour. Res., 11, 742-744, 1975.

Campbell, F. M. A., Nienow, P. W., and Purves, R. S.: Role of the supraglacial snowpack in mediating meltwater delivery to the glacier system as inferred from dye tracer investigations, Hydrol. Process., 20, 969-985, 2006.

Clarke, G. K. C., Jarosch, A. H., Anslow, F. S., Radić, V., and Menounos, B.: Projected deglaciation of western Canada in the twenty-first century, Nat. Geosci., 8, 372-377, 2015.

Colbeck, S. C.: The capillary effects on water percolation in homogeneous snow, J. Glaciol., 13, 85-97, 1974.

Cuffey, K. M. and Paterson, W. S. B.: The Physics of Glaciers, 4th Edn., Academic Press, Amsterdam, 2010.
Dyurgerov, M. B.: Mountain glaciers at the end of the twentieth century: global analysis in relation to climate and water cycle, Polar Geogr., 25, 241-336, 2001.

Ebrahimi, S. and Marshall, S. J.: Parameterization of incoming longwave radiation at glacier sites in the Canadian Rocky Mountains, J. Geophys. Res.-Atmos., doi:10.1002/2015JD023324, in press, 2015.

Engelhardt, M., Schuler, T. V., and Andreassen, L. M.: Sensitivities of glacier mass balance and runoff to climate perturbations in Norway, Ann. Glaciol., 56, 79-88, 2015.

Favier, V., Wagnon, P., Chazarin, J. P., Maisincho, L., and Coudrain, A.: One-year measurements of surface heat budget on the ablation zone of Antizana Glacier 15, Ecuadorian Andes, J. Geophys. Res.-Atmos., 109, 1-15, doi:10.1029/2003JD004359, 2004.

Gerbaux, M., Genthon, C., Etchevers, P., Vincent, C., and Dedieu, J. P.: Surface mass balance of glaciers in the French Alps: distributed modeling and sensitivity to climate change, J. Glaciol., 51, 561-572, 2005.

Giesen, R. H., Van den Broeke, M. R., Oerlemans, J., and Andreassen, L. M.: The surface energy balance in the ablation zone of Midtdalsbreen, a glacier in southern Norway: Interannual variability and the effect of clouds, J. Geophys. Res.-Atmos., 113, 1-17, doi:10.1029/2008JD010390, 2008.

Greuell, W. and Smeets, P.: Variations with elevation in the surface energy balance of the Pasterze (Austria), J. Geophys. Res.Atmos., 106, 31717-31727, 2001.

Hirose, J. M. R. and Marshall, S. J.: Glacier meltwater contributions and glacio-meteorological regime of the Illecillewaet River Basin, British Columbia, Canada, Atmos.-Ocean, 51, 416-435, doi:10.1080/07055900.2013.791614, 2013.

Hock, R.: Glacier melt: a review of processes and their modelling, Prog. Phys. Geogt., 29, 362-391, 2005.

Hock, R. and Holmgren, B.: A distributed surface energy-balance model for complex topography and its application to Storglaciären, Sweden, J. Glaciol., 51, 25-36, 2005.

Huss, M. and Fischer, M.: Sensitivity of very small glaciers in the Swiss Alps to future climate change, Cryosph. Sci., 34, 1-17, doi:10.3389/feart.2016.00034, 2016.

Klok, E. J. and Oerlemans, J.: Model study of the spatial distribution of the energy and mass balance of Morteratschgletscher, Switzerland, J. Glaciol., 48, 505-518, 2002.

Klok, E. J. and Oerlemans, J.: Modelled climate sensitivity of the mass balance of Morteratschgletscher and its dependence on albedo parameterization, Int. J. Climatol., 24, 231-245, 2004.

Klok, E. J., Nolan, M., and Van den Broeke, M. R.: Analysis of meteorological data and the surface energy balance of McCall Glacier, Alaska, USA, J. Glaciol., 51, 451-461, 2005.

Lhomme, J. P., Vacher, J. J., and Rocheteau, A.: Estimating downward long-wave radiation on the Andean Altiplano, Agr. Forest Meteorol., 145, 139-148, 2007.

Liou, K. N.: An Introduction to Atmospheric Radiation, 2nd Edn., Academic Press, Amsterdam, 583 pp., 2002.

Marshall, S. J.: Meltwater runoff from Haig Glacier, Canadian Rocky Mountains, 2002-2013, Hydrol. Earth Syst. Sci., 18, 5181-5200, doi:10.5194/hess-18-5181-2014, 2014.

Marzeion, B., Cogley, J. G., Richter, K., and Parkes, D.: Attribution of global glacier mass loss to anthropogenic and natural causes, Science, 345, 919-921, 2014. 
Mesinger, F., DiMego, G., Kalnay, E., Mitchell, K., Shafran, P. C., Ebisuzaki, W., Jovic, D., Woollen, J., Rogers, E., Berbery, E. H., and Ek, M. B.: North American Regional Reanalysis, B. Am. Meteorol. Soc., 87, 343-360, 2006.

Oerlemans, J. and Fortuin, J. P. F.: Sensitivity of glaciers and small ice caps to greenhouse warming, Science, 258, 115-117, 1992.

Oerlemans, J. and Klok, E. J.: Energy balance of a glacier surface: analysis of AWS data from the Morteratschgletscher, Switzerland, Arct. Antarct. Alp. Res., 34, 115-123, 2002.

Oerlemans, J., Anderson, B., Hubbard, A., Huybrechts, P., Johannesson, T., Knap, W. H., Schmeits, M., Stroeven, A. P., Van de Wal, R. S. W., Wallinga, J., and Zuo, Z.: Modelling the response of glaciers to climate warming, Clim. Dynam., 14, $267-$ 274, 1998

Ohmura, A.: New temperature distribution maps for Greenland, Zeitschrift für Gletscherkunde und Glazialgeologie, 23, 1-45, 1987.

Ohmura, A.: Physical basis for the temperature-based melt-index method, J. Appl. Meteorol., 40, 753-761, 2001.

Oke, T. R.: Boundary Layer Climates, 2nd Edn., Psychology Press, New York, 339-356, 1987.
Radić, V. and Hock, R.: Regionally differentiated contribution of mountain glaciers and ice caps to future sea-level rise, Nat. Geosci., 4, 91-94, 2011.

Sedlar, J. and Hock, R.: Testing longwave radiation parameterizations under clear and over-cast skies at Storglaciaren, Sweden, The Cryosphere, 3, 75-84, doi:10.5194/tc-3-75-2009, 2009.

Sicart, J. E., Hock, R., and Six, D.: Glacier melt, air temperature, and energy balance in different climates: The Bolivian Tropics, the French Alps, and northern Sweden, J. Geophys. Res., 113, 1-11, doi:10.1029/2008JD010406, 2008.

Wagnon, P. W., Ribstein, P., Francou, B., and Pouyaud, B.: Annual cycle of energy balance of Zongo Glacier, Cordillera Real, Bolivia, J. Geophys. Res., 104, 3907-3923, 1999.

Wagnon, P. W., Sicart, J. E., Berthier, E., and Chazarin, J. P.: Wintertime high-altitude surface energy balance of a Bolivian glacier, Illimani, $6340 \mathrm{~m}$ above sea level, J. Geophys. Res., 108, 4177, doi:10.1029/2002JD002088, 2003. 